Submitted to Acta Materialia, February-2016

\title{
Quantification of dislocations densities in zirconium hydride by X-ray line profile analysis
}

\author{
M. A. Vicente Alvarez ${ }^{1}$, J. R. Santisteban ${ }^{1}$, P. Vizcaíno ${ }^{2}$, G. Ribarik ${ }^{3,4}$, T. Ungar ${ }^{4}$ \\ ${ }^{1}$ Neutron Physics Department, Centro Atómico Bariloche, Comisión Nacional de Energía Atómica, \\ Argentina \\ ${ }^{2}$ Zirconium Technology Department, Centro Atómico Ezeiza, Comisión Nacional de Energía Atómica, \\ Argentina \\ ${ }^{3}$ Laboratory of Excellence on Design of Alloy Metals for low-mAss Structures (DAMAS), \\ Université de Lorraine, France \\ ${ }^{4}$ Department of Materials Physics, Eötvös University Budapest, Budapest H-1518 POB, Hungary
}

\begin{abstract}
Zirconium-based components in nuclear power plants are embrittled by precipitates of $\delta$ zirconium hydride, which involves a martensitic-type transformation of the hexagonal $\alpha-\mathrm{Zr}$ lattice into the face-centered cubic Zr sublattice of the hydride. As a result, the hydride precipitates have a complex and heavily distorted internal structure that manifests as broad peaks in X-ray diffraction experiments. By a detailed analysis of the peak widths measured for different crystal planes we have found that most of this broadening is the result of dislocations. The analysis also showed that $\delta$-hydride has very anisotropic mechanical elastic properties, in agreement with ab-initio simulations presented in the literature.

Provided with this peak-broadening model, we have quantified dislocation densities within $\delta$-hydrides precipitated in several $\mathrm{Zr}$ alloys, by analyzing previously published $\mathrm{X}$-ray diffraction experiments performed at three synchrotron X-ray sources. The specimens investigated correspond to components affected by different hydride embrittling processes, namely: (i) samples from various components, charged in the laboratory with $\mathrm{H}$ contents in the 250 wt ppm range, (ii) laboratory-produced hydride blisters in $\mathrm{Zr} 2.5 \% \mathrm{Nb}$ pressure
\end{abstract}


tubes; and (iii) Zircaloy-4 specimens machined from cooling channels of Atucha I nuclear power plant after 10 years in-service, containing $\sim 140 \mathrm{wt}$ ppm of equivalent $\mathrm{H}$ content and subjected to an estimated fast neutron fluence of $\sim 10^{22}$ neutrons $/ \mathrm{cm}^{2}$. Results show that dislocations densities in the $\delta$-hydrides are large $\left(5-20 \times 10^{15} \mathrm{~cm}^{-2}\right)$ and vary among the different specimens. We also found that dislocations densities in the hydride are proportional to the fraction of hydrides already formed in the matrix, which was interpreted as the effect of matrix hardness in the precipitate structure.

*Corresponding author: Miguel Ángel Vicente Alvarez

Centro Atómico Bariloche

San Carlos de Bariloche (8400), Argentina

Email: m.a.vicente@cab.cnea.gov.ar

Tel. +54-2944-44 5154, Fax +54-2944-445299 


\section{Introduction}

Zirconium alloys are widely used in the nuclear industry due to their low neutron absorption, good mechanical properties and corrosion resistance at operation temperatures. $\mathrm{Zr}$ alloys are embrittled by $\mathrm{H}$ absorbed in-service, which precipitates as a brittle hydride phase. Hydride embrittlement may occur mainly through three mechanisms:

i) At relatively low $\mathrm{H}$ concentrations $(<1200 \mathrm{wt}$ ppm $\mathrm{H})$, small hydride precipitates reduce the overall strength of these alloys, with the impact on mechanical properties being highly dependent on the size, shape and orientation of the precipitates. A ductile-brittle transition is observed in Zircaloy-4 when the $\mathrm{H}$ content is higher than a critical value which depends on the alloy microstructure $[1,2]$.

ii) In thermal gradients $\mathrm{H}$ concentrates at cold regions, forming hydride rims or blisters, i.e., macroscopic regions with very high $\mathrm{H}$ content $(\sim 12000-16000$ wt ppm $\mathrm{H})$. This affects the long term storage of spent fuel from nuclear power plants [3], and it has produced the failure of pressure tubes in the past [4].

iii) Over long operational periods, stressed components such as pressure tubes or welded parts may suffer from Delayed Hydride Cracking [5], a failure mechanism where crack growth occurs by repeated precipitation and fracture of small hydrides at the crack tip [6].

In all of these situations $\mathrm{H}$ precipitates as $\delta$-hydride $\left(\mathrm{ZrH}_{\mathrm{x}}\right.$ with $1.6<\mathrm{x}<1.64$ at room temperature), one of the four compound phases found in the $\mathrm{Zr}-\mathrm{H}$ system, which has a density $\sim 17 \%$ lighter than pure $\operatorname{Zr}[7]$. $\delta$-phase precipitates appear as plateletes to the optical microscope, but at higher magnification these platelets are observed to be in fact composed by clusters of smaller sword-like hydrides [8]. The $\delta$ hydride is a defected structure in which the protons occupy approximately $3 / 4$ of the available tetrahedral interstitial sites of a face-centered cubic $\mathrm{Zr}$ sub-lattice with an almost constant lattice parameter for the full range of $\mathrm{H}$ composition $(\sim 4.779 \AA$ at room temperature $)[9,10$, 
$11,12]$. Understanding the mechanical response and eventual fracture of embedded $\delta$ hydride precipitates due to applied loads is essential to model, and eventually mitigate embrittlement [13]. This requires knowledge of the elastic constants and active modes for plastic deformation of the $\delta$-hydride. Also central to all models is a quantification of the stress state and plastic deformation within and around the hydride precipitates that results from accommodation of the localized volume change involved in the phase transformation $\left(\alpha-\mathrm{Zr}+x \mathrm{H} \rightarrow \delta-\mathrm{ZrH}_{x}\right)$. Large uncertainties still exist in the literature about these basic aspects of hydride deformation, mainly due to the experimental difficulties associated to investigate the mechanical response of such small precipitates embedded within the bulk Zr matrix.

So, information about the elastic constants and deformation modes has been obtained from tests performed on bulk, homogeneous, crack-free hydrides produced from pure $\mathrm{Zr}$ in a modified Sieverts apparatus $[14,15,16,17]$ and, more recently, also from $\mathrm{Zr} 2.5 \% \mathrm{Nb}$ [18]. Microscopic observations after indentation tests [19] and after compression tests [15], show that plastic deformation of $\delta$-hydride involves both slip and twinning. Slip on the $\{111\}<110>$ system is the dominant deformation mechanism for as-produced single-phase bulk $\delta$-hydride between room temperature and $250^{\circ} \mathrm{C}[15,19]$. Dislocation lines and twin bands on a $\{110\}$ twin plane are readily observed in TEM images as intrinsic defects in the as-produced bulk material [19].

However, the results on bulk hydrides cannot be directly extrapolated to characterize the response of small hydride precipitates to external loads because of the constraining effect of the metal matrix. Fracture always precedes any measureable plastic deformation in tensile tests of bulk pure $\delta$-hydride. On the other hand, recent in-situ synchrotron X-ray diffraction experiments during mechanical testing have revealed the details of the elastic and plastic response of the hydride precipitates in uniaxial tests in Zircaloy-2 [20] and in 
Zircaloy-4 [21]; and in notched CT specimens [22,23]. There is still no agreement about the interpretation of the response of hydride precipitates to uniaxial loads.

From the information reported for bulk $\delta$-hydrides we can assume that plastic deformation of the hydride precipitate in $\alpha \mathrm{Zr}$ results mainly from slip. Hence, the plastic response and eventual fracture of hydride precipitates to applied loads would be greatly dependent on the dislocation density within the hydride prior to the test. High dislocations densities have been reported in TEM observations of $\delta$-hydride precipitates embedded in $\mathrm{Zr} 2.5 \% \mathrm{Nb}$ [8] and in Zircaloy-4 [24, 25]. In the latter case, dislocation densities within hydride precipitates have been estimated to be $\sim 1.1-1.5 \times 10^{15} \mathrm{~m}^{-2}$ for Zircaloy-4 containing $\sim 1000$ 2000 wt ppm H, both from TEM observations [24] and from neutron diffraction peak profile analysis [25].

Here we present measurements of dislocation densities within hydride precipitates present in specimens affected by different hydride embrittling processes, namely: (i) samples from various components, charged in the laboratory with $\mathrm{H}$ contents in the $<300$ wt ppm range, (ii) laboratory-produced hydride blisters in $\mathrm{Zr} 2.5 \% \mathrm{Nb}$ pressure tubes; and (iii) Zircaloy-4 specimens machined from cooling channels of Atucha I nuclear power plant after 10 years in-service, containing $\sim 140 \mathrm{wt}$ ppm of equivalent $\mathrm{H}$ content and subjected to an estimated fast neutron fluence of $\sim 10^{22}$ neutrons $/ \mathrm{cm}^{2}$. The wide variety of specimens investigated allowed an estimation of the range of dislocations densities existing on the hydrides present in typical nuclear components.

Dislocation densities were obtained through a detailed qualitative and quantitative analysis of peak shape measured for different hydride reflections in synchrotron X-rays diffraction experiments. The dependence of peak width on crystal reflection was interpreted in terms of the results obtained from fitting of the experimental diffractograms by the convolutional multiple whole profile (CMWP) procedure [26, 27]. This model gives as output a 
theoretical diffractogram which can be directly compared to the experimental one, where different contributions to the peak shape are included: instrumental broadening, particle size, dislocation density with the corresponding contrast factors and planar defects as twinning and stacking faults.

This paper is organized as follows. Section 2 gives a brief description of the different samples investigated, and the synchrotron X-ray diffraction facilities used to test them. Section 3 presents a thorough qualitative and quantitative study of the characteristic dependence observed for the physical broadening of $\delta$ hydride lines $(\delta-\{h k l\})$ on the inverse of the interplanar distance $\left(K=1 / d_{\mathrm{hkl}}\right)$. Section 4 presents the line profile analysis for the specimens, which provides information on the accumulation of plastic deformation within $\delta$-hydride precipitates as a response to neutron irradiation, microstructure and compositional variations at the time of precipitation. Section 5 discusses the present findings in terms of existing knowledge about the plastic deformation of $\delta$-hydride precipitates. 


\section{Samples and testing}

The diffraction experiments analyzed here were performed over the last six years at three synchrotron X-ray facilities in USA and Brazil. Those experiments were originally devised to characterize other aspects of hydride precipitates, and their findings have been published elsewhere [28]. Those studies were based on the analysis of the position and intensity of the observed diffraction peaks, but over the years it became clear that $\delta$-hydride peaks were considerable wider than $\alpha-Z r$ peaks, and presented a very characteristic pattern on reflection index. This is exemplified in Figure 1, showing a detail of a diffractogram registered for a hydride blister, at a location where the volume fractions of $\alpha-\mathrm{Zr}$ and $\delta$ hydride were nearly equal. The $\delta$-(220) and $\delta$-(200) peaks are considerably wider than the $\alpha-(11-20)$ and $\alpha-(10-11)$ peaks, respectively, even when the instrumental resolution is almost identical, due to the close proximity between the $\alpha$ and $\delta$ peaks displayed in the figure. This motivated a thorough analysis of peak width, in order to extract some additional information from those past experiments.

The experiments analyzed in this work were chosen because they represent examples for several of the hydride degradation mechanisms mentioned in the Introduction; but also because they provide an insight on how plastic deformation of the $\delta$-hydride precipitate depends on neutron irradiation, and on the microstructure and hydride concentration of the Zr-alloy. The chemical compositions of the specimens studied here and the synchrotron beamlines used for testing are listed in Table 1. In the section below, we provide only a

brief account about specimen preparation and experimental methods for the different specimens, and the reader is referred to the original papers for additional information.

\subsection{Hydride blisters in $\mathrm{Zr} 2.5 \% \mathrm{Nb}$ pressure tubes}


A hydride blister was grown on a coupon machined from a CANDU pressure tube following the procedure described in Refs [29]. In brief, the procedure consists of charging coupons to a concentration of $\sim 160$ wt ppm $\mathrm{H}$ from $\mathrm{H}$ gas at $320^{\circ} \mathrm{C}$ using Sieverts-type device. After that, the $\mathrm{H}$ distribution is homogenized without affecting the microstructure of the material, by annealing at $400^{\circ} \mathrm{C}$ for 1 hour. A blister was produced on the outer surface of the sample by pressing an aluminium cold finger $\sim 200^{\circ} \mathrm{C}$ while the sample was kept in an electric furnace at $\sim 320^{\circ} \mathrm{C}$ for 1650 hours. X-ray diffraction experiments were performed at beamline 1-ID of the Advanced Photon Source at Argonne National Laboratory, with a monochromatic beam of $0.15 \AA$ wavelength and an area detector (2048x2048 pixels of $200 \times 200 \mu \mathrm{m}^{2}$ pixel size) located at $1.948 \mathrm{~m}$ from the sample [28]. The blister is almost fully composed of $\delta$-hydride with just a small fraction of $\gamma$ hydride present near the blister-matrix interface. Figure 2-(a) displays the cross section of the blister on the axial-radial plane of the pressure tube. Below the surface, the blister has a semi-ellipsoidal shape up to a maximum depth of around $750 \mu \mathrm{m}$ from the tube outer surface. Several cracks are clearly visible on the blister surface. Outside the blister, hydrides appear as dark horizontal parallel lines on the white background corresponding to the metal matrix. Diffraction images were obtained at different positions along a line parallel to the surface of the tube, as indicated in the figure. The hydride volume fraction within the blister along Line $\mathrm{X}$ and Line $\mathrm{Y}$ are also shown in Figure 2. These curves were determined from the variation in the intensity of the hydride peaks. At the center, the blister is formed by $80 \%$ of $\delta$-hydride and $20 \%$ of $\alpha$-Zr. This corresponds to a concentration of about $14500 \mathrm{wt}$ ppm of $\mathrm{H}$, which falls to approximately $3200 \mathrm{wt}$ ppm $\mathrm{H}$ near the blister-matrix interface.

Instrumental broadening was determined by measuring a reference $\mathrm{LaB}_{6}$ specimen. Data processing included correcting the $2 \mathrm{D}$ diffractograms by dark current, flat-field and spatial 
distortion corrections. Following, the diffraction images were converted into $2 \theta$ diffractograms that are analyzed as conventional $\theta-2 \theta$ scans. Typical diffractograms obtained at the base material, near the blister/matrix interface, and at the blister center are presented in Figure 3. $\alpha-\mathrm{Zr}$ lines appear as sharp peaks as indicated in red, witch decrease in intensity as entering into the blister. By contrast, at the blister center the diffractogram is dominated by seven, well defined $\delta$-hydride peaks (indicated by dotted vertical lines), and most $\alpha-Z r$ peaks are barely visible. Quick comparison of Figure 3-a and 3-c reveals that $\delta$ hydride peaks are much broader than $\alpha-\mathrm{Zr}$ peaks over the whole $2 \theta$ range. At the blister interface the $\delta(111)$ and $\alpha(10-10)$ peaks have comparable intensities, and whilst the $\delta(200)$, $\delta(220)$ and $\delta(311)$ peaks are still well defined, the higher order $\delta(222), \delta(400)$ and $\delta(331)$ peaks are diffused in the background, or partially overlapped with intense $\alpha$ peaks. Outside the blister, only the most intense $\delta$-hydride peaks are visible, appearing in some cases as shoulders of the strong $\alpha-Z r$ reflection.

\subsection{Irradiated Zircaloy-4 specimens from cooling channels of Atucha I power plant}

These samples were extracted from a cooling channel after 10 years in service at the Atucha I nuclear power plant, Argentina (Zry-IR). These vertical cooling channels consist of $6 \mathrm{~m}$ long Zircaloy-4 tubes, produced by bending and axial welding of cold rolled sheets, and are designed to withstand the entire lifetime of the reactor. The fuel elements are located within the channels and cooled by heavy water that circulates upwards, increasing its temperature from $250^{\circ} \mathrm{C}$ at the bottom to $305^{\circ} \mathrm{C}$ at the top. The channels are subjected to a fast neutron flux $(>1 \mathrm{MeV})$ peaking at the center of the channels, at a nominal value of $3.76 \times 10^{13}$ neutrons $/\left(\mathrm{cm}^{2} \mathrm{sec}\right)$. Three Zircaloy-4 specimens were extracted from the center of the reactor, where the operation temperature is $\sim 275^{\circ} \mathrm{C}$, after an estimated neutron fluence of $\sim 10^{22}$ neutrons $/ \mathrm{cm}^{2}$. The original material contained a $\mathrm{H}$ concentration of about $15 \pm 5$ wppm. The corrosion reaction occurring in service between Zircaloy-4 and the 
heavy water while in service releases deuterium (D), part of which is incorporated into the metal. In this way, the total equivalent hydrogen isotope concentration in wt ppm is given by $\mathrm{H}_{\mathrm{eq}}=\mathrm{H}+1 / 2 * \mathrm{D}$, where $\mathrm{H}$ is the hydrogen content of the original material. The $\mathrm{H}_{\mathrm{eq}}$ content in the material from the center of the channel was $140 \mathrm{wt}$ ppm of $\mathrm{H}$, as measured with a LECO RH-404 meter calibrated with deuterium gas. Synchrotron X-ray diffraction experiments were performed at the XRD\#1 beamline of the LNLS, in Campinas, Brazil, with a monochromatic beam of $1.542484(1) \AA$ wavelength and with a $\theta / 2 \theta$ layout in reflection geometry. Angular scans performed with a $0.05^{\circ}$ step over a $2 \theta$ range of $20^{\circ} \leq$ $2 \theta \leq 130^{\circ}$. After an initial measurement of each specimen, two of the specimens were further annealed to recover irradiation damage, and re-measured. One specimen (Zry-4-IR$400 \mathrm{C}-72 \mathrm{~h}$ ) was annealed at $400^{\circ} \mathrm{C}$ for 72 hours, and the other specimen (Zry-4-IR-600C$24 \mathrm{~h})$ at $600^{\circ} \mathrm{C}$ for 24 hours. An un-irradiated specimen (Zry-H260) from the same Zircaloy-4 sheet loaded with 260 wt ppm of $\mathrm{H}$ by the cathodic charge technique and homogenized by annealing at $550^{\circ} \mathrm{C}$ during $3 \mathrm{~h}$ was also measured for comparison.

A $\mathrm{Zr}$ powder of large grain size was used as reference specimen to subtract the instrumental broadening. The reference powder was produced by filing of un-irradiated Zircaloy-4 sheet, followed by an annealing treatment in order to obtain a fullyrecrystallized and strain-free microstructure. The integral breadth of this specimen was almost undistinguishable from a LaB6 standard. Use of Zr powder as standard avoids extrapolation of the instrumental broadening to the angular position of the $\alpha \mathrm{Zr}$ diffraction peaks.

\section{Physical broadening and integral breadths of $\delta$-zirconium hydride}

\subsection{Data analysis}

The measured peak profile or experimental broadening, is the result of the convolution between the instrumental broadening of the diffractometer and the physical broadening, 
introduced by the sample [30]. The instrumental broadening results from the wavelength and angular spread of the incident beam, and the finite sizes of beam, sample and detectors. It is commonly defined by measuring a "perfect" or standard powder sample. The physical broadening represents the departure of the real material from a perfect and infinite array of atomic layers. Hence, information about the size of the diffracting domains and their internal strain state is estimated from the magnitude and angular dependence of the physical broadening rather than from the experimental broadening,

The method implemented here to obtain the physical broadening (PB) from the experimental broadening (EB) and the instrumental broadening (IB) is briefly described in Figure 4, which corresponds to a narrow $2 \theta$ range of the diffractogram presented in Figure 3-b. The same data range shown in Figure 4 was also displayed in Figure 1-b, but plotted on $d$-spacing scale instead of the instrumental $2 \theta$ scale. For every diffractogram, we first determine the position, intensity and shape of all peaks (for both $\delta$-hydride and $\alpha-Z r$ ), by performing a least-squares refinement using a pseudo-Voigt peak profile on top of a linear background. As exemplified by Figure 4-(a), simultaneous fitting of two or more peaks becomes necessary for some angular ranges, due to the superposition of $\alpha-\mathrm{Zr}$ and $\delta$ hydride peaks. In this way, it is possible to obtain valuable information from partially overlapping peaks. The black solid line shows the refined curve to the experimental data (open symbols), whilst the dashed blue and dashed red lines represent the individual peaks contributing to the refined profile. Background is shown as a flat dashed magenta line. The instrumental broadening for the $2 \theta$ angle corresponding to the $\delta$-(200) peak is represented by the dashed green line, as estimated from the diffractogram recorded for $\mathrm{LaB}_{6}$ standard sample. As $\mathrm{LaB}_{6}$ peaks appear at different $2 \theta$ angles than $\alpha$-Zr and $\delta$-hydride peaks, the instrumental peak shown in the figure was calculated by extrapolation of the pseudo-Voigt coefficients measured over the full $2 \theta$ range for $\mathrm{LaB}_{6}$. The figure shows that the $\alpha-(10-11)$ 
peak (blue) is slightly broader than the instrumental broadening, whilst the $\delta$-(200) peak (red) is considerably much broader.

The physical broadening for each peak is obtained by means of a deconvolution process, based on the Fourier transforms of the individual peaks shown in Figure 4-a. Figure 4-b shows in red the real part of the Fourier transform of the experimental $\delta$-(200) reflection, FT(Exp), and in green line the Fourier transform of the corresponding instrumental broadening, FT(Instr). These Fourier transforms are numerically calculated from the fitted and estimated pseudo-Voigt profiles shown in Figure 4-a in identical colors and lines. FT(Exp) and FT(Instr) are presented as a function of a characteristic length $L$ (in Amstrongs). Due to the intrinsic properties of the convolution procedure, the Fourier transform for the physical broadening, FT(PB), can be directly evaluated as the ratio of those two Fourier transforms, FT(PB)= FT(EB)/FT(IB), shown by the magenta points in Figure 4-b. For the (200) reflection of the $\delta$-hydride, FT(PB) and FT(Exp) are very similar because the FT(Instr) is almost constant over the variation range of FT(Exp). This means that from the point of view of some of the hydride peaks the instrument is seen as having an almost perfect resolution, so any errors due to the deconvolution process are likely to be very small. The physical broadening, PB, shown in Figure 4-c, is evaluated by further Fourier transformation of FT(PB), shifted in the $2 \theta$ scale so to be centered at zero.

For further analysis we use the integral breadth, a simple scalar magnitude quantifying the physical broadening, calculated as the ratio between the area and the maximum intensity of the peak displayed in Figure 4-c. Integral breadths are commonly expressed in terms of the dispersion $\Delta K$ of the momentum exchange vector involved in the diffraction process, $K=1 / d=2 \sin \theta / \lambda$, with $d$ the interplanar distance. So, integral breadths are expressed in units of the inverse of length (here we use $\mathrm{nm}^{-1}$ ). This allows comparisons between integral breadths measured using different wavelengths $\lambda$, as we have done in the present study. 


\subsection{Integral breadth dependence on the modulus of the momentum exchange $K$}

Table 2 lists the integral breadths quantifying the physical broadening measured for all samples studied in this work. In the case of the blister, the values are reported for the different positions indicated in Figure 2, which the $\mathrm{H}$ concentrations shown in the same figure. Moreover, the reported breadths correspond to diffractograms constructed from the diagonal section of the square images collected by the detector. For this azimuthal section, a greater number of diffraction rings are accessible. Figure 5 shows a graphical representation of the data presented in Table 2. As it is standard practice, integral breadths are plotted as a function of the modulus of the momentum exchange vector $\boldsymbol{K}$. For better clarity, only some of the data presented in the table are included in the plot, yet the main trends are still clear from the figure. The results for $\alpha-\mathrm{Zr}$ are also included for comparison. Comparison of the results obtained from different specimens for a fixed $K$ value (a column in the Table corresponding to a particular $(h k l))$ show that integral breadths of the $\delta$ hydride phase depend on both $\mathrm{H}$ concentration and irradiation damage condition; whilst show little change with the microstructure of the sample where it was grown (Zircaloy or $\mathrm{Zr}-2.5 \mathrm{Nb})$.

In particular for the $\delta$-(111) peak, the integral breadth shows a net increase of $\sim 80 \%$ from the blister edge (3200ppm) to its center (14500ppm) along Line X, and a similar behavior is observed for the other peaks. By contrast, the values obtained at the blister edge are rather similar to those obtained for the Zry-H260 sample, despite great differences in microstructure between the pressure tube (lamellar grains of $\sim 0.1 \mu \mathrm{m}$ thickness) and the Zircaloy-4 sheet material (round, equiaxed grains of $\sim 10 \mu \mathrm{m}$ size).

Irradiation damage broadens the peaks due to the introduction of defects in the crystal structure. This is clear from comparison of the results obtained for sample Zry-IR with those from Zry-H260, a non-irradiated specimen with similar $H$ content. The $\delta$-(111) integral breadth increases in $\sim 40 \%$ due to irradiation, and the $\delta$-(222) peak in about $100 \%$. 
The specimen annealed at $600^{\circ} \mathrm{C}$ (Zry-IR-600C-24h) has integral breadths almost identical to those of the non-irradiated material (Zry-H260), whilst intermediate values are found for the specimen annealed at $400^{\circ} \mathrm{C}$ (Zry-IR-400C-72h).

The dependence of integral breadths of $\delta$-hydride peaks with $K$ is complex, but a clear pattern manifests consistently in all samples. The lowest integral breadths are found for the compact planes $\delta$-(111) peaks and its higher order reflection $\delta$-(222), whilst considerably much larger values are found for all other peaks. It is worth noting that reflections with similar $K$ values, like $\delta$-(111) and $\delta$-(200), have breadths differing in $\sim 700 \%$. On the other hand, we also observe that for the same diffracting plane breadths of higher order peaks are always greater than lower order ones. This is particularly clear for the $\delta$-(200) and $\delta$-(400) reflections. This marked slope of breadth with $K$ for the same diffracting planes suggests that strain broadening plays a central role in line broadening. Except for the mentioned $\delta$ (111) and $\delta$-(222) peaks, integral breadths of the hydride precipitates are an order of magnitude higher than those found for the $\alpha-Z r$ matrix of the pressure tube (see Figure 5). Similar differences were also observed for the Zry-H260 specimen. These results show that $\delta$-hydrides have always a highly disordered crystal structure, despite the environment where they are formed. Moreover, a characteristic "serrated-like" variation with $K$ indicates a complex dependence of peak widths with reflection order ( $h k l)$; and suggests that valuable information about the specific type of disorder within the hydride crystal structure is contained within such figure. However, many physical effects can produce broadening of diffraction peaks (grain size, dislocations, stacking faults, intergranular stresses, etc). Identification of the actual origin(s) of the observed broadening is essential for proper interpretation of the experimental results. With this in mind, we have also investigated the dependence of integral breadths with the direction of the momentum exchange, as described next. 


\subsection{Integral breadth dependence on the direction of the momentum exchange $K$}

The direction of the momentum exchange vector is usually not considered in line profile analyses of polycrystalline materials, but it is important for experiments performed on highly textured specimens or for systems containing high levels of internal stress. In such cases, the direction of the momentum exchange vector $\boldsymbol{K}$ is referred to the coordinate system of the macroscopic specimen (tube, plate, etc). Depending on the details of the experimental arrangement, e.g., on the relative orientation between the exchange vector $\boldsymbol{K}$ and the normal to the hydride platelets, such stresses could result into significant broadening of the diffraction peaks. This is because the observed peak is the result of the superposition of the intensity diffracted by a large number of crystallites, suitable oriented to reflect the incident beam into the detector, and grain stresses may introduce different strain states among those crystallites. Hence, whilst the individual peak associated to each crystallite may be narrow, the combined contribution of all peaks (shifted in position due to stress) could produce a wide or even asymmetric diffraction peak. The effect of grain stresses may manifest as differences in the integral breadth measured along different directions of the specimen. Such inter-granular stresses dominates peak broadening of $\alpha$-Zr peaks in non-annealed cold-drawn $\mathrm{Zr} 2.5 \% \mathrm{Nb}$ pressure tubes [31], and partially account for the differences observed in integral breadths measured along different tube directions [32]. However, according to a recent study, they are almost negligible for annealed tubes [33]. Besides grain stresses, hydride precipitates in tubes and plates present strong preferred orientations that depend on the crystallographic texture of the parent $\mathrm{Zr}$-matrix. Microstructural differences between grains belonging to different texture components of the hydride could also change the integral breadths measured along different directions of the specimen.

The dependence of the hydride line shape with the direction of the momentum exchange is easily accessible in synchrotron X-ray diffraction experiments in transmission geometry 
with a $2 \mathrm{D}$ detector. For the transmission geometry used in the high-energy synchrotron experiments analyzed here (APS), the Debye rings map into lines on a pole figure plot [28]. Due to the low scattering angles involved, each diffraction ring provides information for $K$ vectors with directions almost perpendicular to the direction of the incident $X$-ray beam. This is so because the diffracting signal comes only from crystals whose plane normal lay parallel to the scattering vector. Hence, variations of line shape with the azimuthal angle around the Debye ring reveal microstructural differences between hydride precipitates of different orientations. Figure 6 presents the dependence with azimuthal angle of the integral breadths measured at two locations within the blister. The results are plotted only for the first quadrant due to the orthorhombic symmetry of the sample. For this experimental geometry, hydrides contributing to the $\delta$ - $(h k l)$ peak at $\phi=0^{\circ}$ are oriented with their ( $h k l)$ plane normal parallel to the radial direction (RD) of the pressure tube, whilst those at $\phi=90^{\circ}$ have their plane normal pointing along the tube axial direction (AD), as indicated by the two arrows. Intermediate values of $\phi$ correspond to hydrides having their plane normals in between those two directions. Peaks with different Miller indexes are identified with different colors and symbols. Due to the square shape of the 2D detector, higher order reflections such as $\delta$-(400) and $\delta$-(331) are only observed over a narrow angular range around the diagonal of the detector $\left(\phi=45^{\circ}\right)$. For lower order peaks such as $\delta$-(222) or $\delta$-(311), missing values are due to poor definition of peak shapes, either because of low intensity or because of partial superposition with intense $\alpha$-Zr peaks. Both plots show little dependence of integral breadths with hydride orientation, with a maximum deviation of $\sim 20 \%$ from the average. So the values reported in Figure 5 and Table 2 for the hydride blister can be considered as being representative of the sample as a whole. 


\section{Quantitative peak profile analyses of $\delta$-hydrides using the convolutional multiple whole profile (CMWP) procedure}

There are two main causes of physical broadening in diffraction experiments, broadly termed as "size effects" and "strain effects", which affect the width of diffraction peaks in different ways [34]. While "size effects" refer to an insufficient number of diffracting planes, increasing the integral breadth of all peaks equally; "strain effects" refer to the displacements of the atoms from their ideal positions, and is more pronounced for those peaks involving higher momentum exchange $K$. Theoretical expressions describing these two contributions to peak broadening for powdered specimens have long been developed $[35,36]$, allowing the use of diffraction experiments to estimate microstructural features such as average particle sizes, and mean square strains within the particles. Similar models can also be applied for microstructural studies on solid polycrystalline aggregates such as metal alloys or compounds. In such cases, however, a multitude of factors, such as stresses, can contribute to the observed peak broadening. On estimating microstructural parameters from peak profile analysis, it must be kept in mind that the measured values are always average projections of the magnitude of interest along the direction of the exchange vector K.

A simple qualitative calculation can show that dislocation broadening is the dominant effects in line broadening in the present case. Intergranular strains (IGS), $\varepsilon_{\mathrm{IGS}}$, and stresses, $\Delta \sigma_{\mathrm{IGS}}$ are related by Hooks low: $\Delta \sigma_{\mathrm{IGS}}=\mathrm{E} \varepsilon_{\mathrm{IGS}}$, where $\mathrm{E}$ is Young's modulus.

Intergranular strains, on the other hand, are related to momentum transfer as: $\varepsilon_{\mathrm{IGS}}=\frac{\Delta \mathrm{K}}{\mathrm{K}}$, where $\Delta \mathrm{K}$ can be measured as the FWHM of peak profiles produced by IGSs. Next we compare the FWHM values, in terms of $\Delta \mathrm{K}$, for dislocation and IGS broadening. Dislocation broadening, $\Delta \mathrm{K}_{\text {Disloc }}$, as shown for example in Figure 5 , for $\delta$-hydride varies 
between 0.1 and $0.5 \mathrm{~nm}^{-1}$. The order of magnitude of broadening caused by IGSs, $\Delta \mathrm{K}_{\mathrm{IGS}}$, can be estimated by assuming that $\Delta \sigma_{\mathrm{IGS}} \cong 250 \mathrm{MPa}[37]$ and $\mathrm{E} \cong 60 \mathrm{GPa}$, providing $\Delta \mathrm{K}_{\mathrm{IGS}}$ in the $\delta$-hydride phase to increase from $4 \times 10^{-3}$ to $4 \times 10^{-2}$ in the $\mathrm{K}$ range of 1 to $10 \mathrm{~nm}^{-1}$, respectively. With these values the relative broadening caused IGSs or dislocations, $\frac{\Delta \mathrm{K}_{\mathrm{IGS}}}{\Delta \mathrm{K}_{\mathrm{Disloc}}}$, is varying between 0.04 and 0.4 . This simple calculation shows that if IGSs would play an important role in the line broadening in the $\delta$ phase then the effect would be increasingly profound in the higher angle peaks. The Williamson-Hall plot in Figure 5 shows, however, that, though peak broadening is strongly anisotropic in terms of $h k l$ dependence, there is no substantial global increase with diffraction angle. This qualitative behavior of the physical FWHM values clearly indicates that the major lattice defects causing line broadening in the $\delta$ phase are dislocations and planar defects with no significant effect of IGSs. The effect of IGSs in the $\alpha-\mathrm{Zr}$ phase can be excluded, as discussed before, since the specimens were annealed before hydration. Therefore, in the present quantitative analysis we will not consider the contribution of hydride internal stresses to line broadening. Besides internal stresses, local variations in stoichiometry $\left(\mathrm{ZrH}_{x}\right)$ between different hydrides, or even within a single hydride [38], could result in peak broadening. However, the negligible dependence of lattice parameter $a$ with $x$ for hydride phase [11], leads us to disregard the contribution of this effect to line broadening.

Computer packages have been developed to estimate the microstructural parameters from peak profile. In particular, the CMWP model has proved to be one of the most efficient methods to do such analysis [26,27]. This software includes the effect of particle size, dislocation density with their corresponding contrast factors, and planar defects like stacking fault and twins. A theoretical diffractogram that depends on the phases present in the material and their microstructural variables is generated and convoluted with an instrumental broadening function to give a diffractogram that can be directly compared to 
the experimental one. An error function is defined as the difference between the theoretical and experimental diffractograms. Then, a least square minimization procedure is used to optimize the microstructural variables of each phase present in the material.

This software was applied for diffractgrams collected at selected points along the blister, for the Zircaloy sample with low H content and for the irradiated Zircaloy sheets too. To illustrate the quality of fitting, Figure 7 shows a comparison between the experimental diffractogram as points and the CMWP output after optimization as blue lines for two different positions in the blister. The error function is shown at the bottom of the figures. The difference between the model and the experiment is small, giving confidence to the method. Figure 8 shows the integral breadths $\Delta K$ predicted by the model plotted as a function of the product of $K$ times the square of the contrast factor $C^{1 / 2}$. This type of graph is known as modified Williamson-Hall plot where a linear regression is expected. In this plots, the $y$-intercept is proportional to the inverse of the particle size, while the slope of the curve is proportional to the dislocation density. The points plotted in Figure 8 are the breadths of the peaks presented in Table 2 (already shown as a function of $K$ in Figure 5) after subtraction of the broadening effect of twinning. The departure of the theoretical points from a perfect line is due to the contribution to line broadening of other effect not included in the model, such as orientation dependence, misfit/intergranular stresses or compositional variations as discussed earlier. Anyway, these differences do not affect the final results of the analysis. It is interesting to note that the contrast factor shifts the abscissa value of the ( $h k l)$ peaks in a way so that the "serrated" shape observed in Figure 5 converts into an almost linear dependence in Figure 8. As a general trend, the slope increases with the total $\mathrm{H}$ content of the sample indicating that the dislocation density in the hydride phase increases with the global $\mathrm{H}$ content. 


\subsection{Dislocation densities results}

Table 3 presents the most relevant microstructural parameters obtained for both phases after fitting with the CMWP software. For hydrides, the total dislocation density, the twin fault probability $\beta$, the effective particle size due to twinning $d_{\text {Twin }}$, the crystallite size $<\mathrm{x}\rangle_{\text {area }}$ and the value of $q$, corresponding to the contrast factor, are presented in the Table. For $\alpha \mathrm{Zr}$, only the total dislocation density and the average crystallite size $\langle\mathrm{x}\rangle_{\text {area }}$ are included as the last two columns of the Table.

Particle size is dominated by twinning, and is in the range of 4-30nm. Parameter $q$ takes values in a narrow range 2.5-2.9. For cubic crystals the average contrast factor changes with (hkl) following $\bar{C}=\bar{C}_{h 00}\left(1-q . H^{2}\right)$, where $\bar{C}_{h 00}$ is the average contrast factors for (h00) reflections and $H^{2}=\left(h^{2} k^{2}+h^{2} l^{2}+k^{2} l^{2}\right) /\left(h^{2}+k^{2}+l^{2}\right)^{2}$ [39]. Both $\bar{C}_{h 00}$ and $q$ depend on the elastic constant of the material and also on the dislocation type (screw or edge). In real materials, the effective contrast factor will be given by the weighted average of $\bar{C}_{\text {screw }}$ and $\bar{C}_{\text {edge }}$ considering the fraction of screw and edge dislocation. From the (hkl) dependence of $\bar{C}$, expressed in the previous equation, a value of $q$ close to 3 means a high strain anisotropy of line broadening, and is actually needed to explain the variations of the peak width from peak to peak seen in Figure 5. In particular, when $q=2.8$, the contrast factor $C_{111}\left(H_{h h h}^{2}=1 / 3\right)$ becomes $\sim 30$ times lower than the contrast factor $C_{200}\left(H_{h 00}^{2}=0\right)$. This is in good correspondence to the observation that (111) and (222) hydride peaks are as narrow as $\alpha Z r$ phase, while (200) and (400) peaks are much broader. The lack of data about the elastic stiffness tensor of $\delta$-hydride makes difficult to assess the accuracy of the value of $q$ obtained from this analysis.

The dislocation density obtained for the hydride phase results one order of magnitude higher than that for $\alpha \mathrm{Zr}$, and depends mainly on the total $\mathrm{H}$ content of the material and on the irradiation condition. For low $\mathrm{H}$ content its value is $\sim 5.10^{15} \mathrm{~m}^{-2}$, and increases up to 
$\sim 3.10^{16} \mathrm{~m}^{-2}$ for massive hydrides, as found at the center of the blister. The dislocation density in the $\alpha \mathrm{Zr}$ matrix is low for the recrystallized non-irradiated Zircaloy-4 sheet $\left(\sim 10^{13} \mathrm{~m}^{-2}\right)$ and for the pressure tube far away from the blister center. As for the hydride phase, the dislocation density of the matrix also increases while introducing into the blister. At the center, values of $3.10^{15} \mathrm{~m}^{-2}$ are found, which are typical of deformed metals. In the highly irradiated material, the dislocation densities in both phases are similar to those found at the blister center. For the hydride, they are estimated to be around $1.10^{16} \mathrm{~m}^{-2}$, while for $\alpha \mathrm{Zr}$ they are approximately $5.10^{14} \mathrm{~m}^{-2}$. Irradiation up to fluences of $10^{22} \mathrm{n} / \mathrm{cm}^{2}$ produces important damage, giving rise to a marked increase of dislocation loops in both hydride and $\alpha \mathrm{Zr}$. Annealing after irradiation produces important recovery of the dislocation structure of the matrix, especially at high annealing temperatures. After $600^{\circ} \mathrm{C}$ treatment the dislocation density in the matrix ends almost identical to that of the nonirradiated material, while for $400^{\circ} \mathrm{C}$, partial recovery of dislocation is observed. Hydrides formed in the partially recovered material $\left(400^{\circ} \mathrm{C}\right)$ show higher breadths than those observed for the fully recovered material $\left(600^{\circ} \mathrm{C}\right)$, copying the trend followed by the matrix.

Figure 9 shows the dependence of the dislocation density in both phases as a function of the distance to the blister center along line $\mathrm{X}$. H concentration curve is superimposed as black squares. Dislocation density takes maximum values at the blister center, where hydride concentration is maximum too, and decreases as hydride concentration reduces. Moreover, there seems to be a one to one dependence between dislocation density in the hydride and $\mathrm{H}$ concentration. The fraction of $\alpha \mathrm{Zr}$ that remains untransformed in the blister also shows a rise in the dislocation density at the center but this increase only manifests for values of $\mathrm{H}$ above $12000 \mathrm{ppm}$. Actually, we consider that the difference in the behavior of hydride and matrix with $\mathrm{H}$ content might be a consequence of the way deformation distributes spatially in both phases. During hydride formation, dislocations are formed in 
the $\alpha \mathrm{Zr}$ matrix preferentially in the vicinity of new hydride, while the material far away remains unaltered. X-ray diffraction signal has contribution from these two regions, so its sensitivity to detect sharply localized deformation is poor. At the blister center, the remnant $\alpha \mathrm{Zr}$ region is reduced in size, and the technique becomes more sensitive to this localized deformation, producing observable changes in the peak widths. In the case of hydrides, due to its small size, deformation would be spread all over its extension, and so X-Ray peak width would be strongly affected by this deformation.

From Table 3 it is clear that for low $\mathrm{H}$ content, the dislocation density in the hydride starts at a value around $2.10^{15}-5.10^{15} \mathrm{~m}^{-2}$, indicating that even for low $\mathrm{H}$ content a high dislocation density is observed in the hydride, probably related to the high volume strain misfit between hydride and matrix.

\section{Discussion}

\subsection{Effects of irradiation and subsequent annealing on dislocation density}

In the irradiated sample, the dislocation density of both hydride and matrix result much higher than in non-irradiated samples with similar $\mathrm{H}$ content. This is an expected result considering the effect of irradiation damage producing dislocation loops during rearrangement of defects. In the particular case under study, irradiation occurs at the inservice temperature of approximately $275^{\circ} \mathrm{C}$. The total content of $\mathrm{H}(\mathrm{D})$ picked up by the cooling channel while in service was $140 \mathrm{ppm}$. According to the solubility curves of $\mathrm{H}$ in $\mathrm{Zr}$ [40], at that temperature 50ppm of the total $\mathrm{H}$ content is in solid solution, while the remnant $90 \mathrm{ppm}$ is forming hydrides. This means that $65 \%$ of the hydrides were irradiated in service, while the other $35 \%$ are hydrides formed during cooling at the reactor shut downs. During recovery annealing after irradiation, the situation changes slightly since for this $\mathrm{H}(\mathrm{D})$ content, hydrides are completely dissolved at temperatures over $360^{\circ} \mathrm{C}$. This 
means that the dislocation density obtained for these irradiated+annealed samples corresponds to non-irradiated hydrides formed in a matrix partially recovered after irradiation. In other words, the lower dislocation densities in the hydrides found in the irradiated+annealed samples compared to the irradiated one is a manifestation of the effect of the formation of hydrides in matrices with different hardness.

\subsection{Effects of $H$ content on dislocation density}

Figure 9 shows that there is an increasing dependence of the hydride dislocation density with $\mathrm{H}$ content in the blister. Moreover, for low H contents, (Zry-H260 sample and far from the blister center along line $\mathrm{Y}$ ) a dislocation density of $2.10^{15}-5.10^{15} \mathrm{~m}^{-2}$ was determined, which is comparable to values observed in deformed metals. Considering that there is a $17 \%$ volume misfit between hydride and $\alpha \mathrm{Zr}$, we associate this high density of dislocations at low $\mathrm{H}$ contents to plastic deformation during hydride formation and growth. In principle, the way plastic straining distributes between hydride and matrix depends on matrix hardness, as shown by Puls [41]. In a hard matrix, deformation transfers mainly to the hydride since matrix can withstand higher stresses before straining. On the contrary, a soft matrix accumulates higher strain reducing the deformation in the hydride. In this context, it is reasonable that higher $\mathrm{H}$ content implies a harder matrix. Two factors are contributing to matrix hardening as $\mathrm{H}$ content increases, a) strain hardening by the presence of dislocations produced by already formed precipitates (as seen in red in Figure 9) and b) precipitate hardening by the presence of other small hydrides that act as barrier for dislocation movement. In this way, during the formation of the blister, new hydrides are formed (or old hydrides growth) in a matrix that is being continuously hardened by the same hydride precipitation/growth process. At the blister center, the matrix is so hard that hydrides form with a highly disordered structure. This may be the reason of the generation 
of cracks in this region. The degree of stresses and deformation that develops at the blister center is so intense that the material cannot withstand its integrity.

Moreover, we can interpret the effect of annealing post irradiation in a similar manner. The material annealed at $400^{\circ} \mathrm{C}$ presents a partially recovered matrix (dislocation density of $1.410^{15} \mathrm{~m}^{-2}$ ), and therefore hydrides formed during cooling in this hard matrix end with a highly disordered structure. On the contrary, annealing at $600^{\circ} \mathrm{C}$ seems to be enough to fully recover the damage produced by irradiation. Hence, hydrides formed in fully recovered and non-irradiated matrices should have similar internal structure, as observed from the experimental integral breadths of Table 2 or from the estimation of de dislocation densities of Table 3 .

\subsection{Interpretation of the $q$ value obtained for hydrides}

The inclusion of anisotropic broadening by dislocations is necessary to obtain good fitting of the experimental points. The huge variation of breadth of the peaks seen experimentally in Figure 5 is followed by the model assuming high contrast factors, which are obtained with values of $q$ close to 3 . As mentioned before $q \sim 2.8$ implies a $\sim 30$ times reduction of broadening effect of dislocation on (111) and (222) peaks compared to (200) peak. For cubic crystals, Ungar et al showed that $q$ depends on the elastic constant of the material and dislocation type. In particular, for f.c.c. crystals parameters $\bar{C}_{h 00}$ and $q$ defining the dependence of the average contrast factor with the Miller indices are given by [39]:

$$
\begin{aligned}
& \bar{C}_{h 00}=a\left[1-\exp \left(-\frac{A_{\mathrm{i}}}{b}\right)+c \cdot A_{\mathrm{i}}+d\right] \\
& q=a\left[1-\exp \left(-\frac{A_{\mathrm{i}}}{b}\right)\right]+c \cdot A_{\mathrm{i}}+d
\end{aligned}
$$

where $A_{\mathrm{i}}$ is the crystal elastic anisotropy $2 \mathrm{c}_{44} /\left(\mathrm{c}_{11}-\mathrm{c}_{12}\right)$, with $c_{i j}$ the components of the stiffness tensor. Equation 2 is valid as long as $q$ keeps below 3, since the average contrast 
factor could not take negative values. The values of $a$ to $d$ depend on the dislocation type, and for edge dislocations they also depend on the $c_{12} / c_{44}$ ratio. In practice, the fraction of screw to edge dislocations $\left(f_{\text {screw }}\right.$ and $\left.f_{\text {edge }}\right)$ is obtained from the experimental $q_{\text {exp }}$ by solving $q_{\text {exp }}=f_{\text {screw }} q_{\text {screw }}+f_{\text {edge }} q_{\text {edge }}$ with $f_{\text {edge }}+f_{\text {screw }}=1$. In order to have solution to this system it is necessary that $q_{\text {exp }}$ lie in between the theoretical $q_{\text {edge }}$ and $q_{\text {screw }}$ curves. In the case of the hydride phase, the elastic constants are unknown; so it is not possible to compare $q \sim 2.5-2.9$ to estimations of $q_{\text {edge }}$ and $q_{\text {screw }}$. However, we can mention that this value of $q$ is slightly higher than those reported in literature for other cubic material with high anisotropy ( $\mathrm{Cu} 2.0$, for $\mathrm{Ni} 2.35$ and for Rb3C60 2.47). In Figure 10 we plot theoretical values of $q_{\text {edge }}$ and $q_{\text {screw }}$, calculated using Eq.(2), as a function of the elastic anisotropy for a f.c.c crystal with different $c_{12} / c_{44}$ ratio. Values of $q_{\text {edge }}$ are always lower than $q_{\text {screw }}$. In the figure the optimum value of $q$ obtained with CMWP is superimposed as an horizontal grey bar. As mentioned above, solutions to the system of equations exist only when $q_{\text {edge }}<q_{\text {exp }}<q_{\text {screw }}$, which means that $A_{i}>4$ for hydrides. This elastic anisotropy is in the range of values found in most materials (0.5-8) [42] and is also in the range of values estimated for $\delta$-hydride from ab-initio calculations $A_{i} \sim 2.35$ [43] and $A_{i} \sim 6.9$ [44]. Despite the actual value of $A_{i}$ for $\delta$-hydrides, which is still unknown, it is clear that the elastic response of this phase is highly anisotropic and reflects through the marked line broadening strain anisotropy. The particular arrangement of $\mathrm{H}$ atoms occupying 6 of the 8 tetrahedral sites of the f.c.c. Zr lattice, presumably filling alternate (111) planes, would be responsible of this behavior. 


\section{Conclusions}

We presented a detail characterization of the peak shape of the $\delta$-hydride diffraction peaks grown in different zirconium alloys and subjected to different environmental conditions. We analyzed the dependence of the integral breadths with the momentum vector $K$ modulus and direction.

A quantitative study of the line shape was done by using the CMWP package. We have found that most of this broadening is the result of dislocations. Particle size is controlled by planar defects, like twinning or faults, giving an effective crystallite size of the order of 10$30 \mathrm{~nm}$. Results show that dislocations densities in the $\delta$-hydrides are large $\left(5-20 \times 10^{15} \mathrm{~m}^{-2}\right)$, much higher than the values observed for the matrix $\left(\sim 10^{14} \mathrm{~m}^{-2}\right)$, and vary among the different specimens. Dislocations densities in the hydride are proportional to the fraction of hydrides already formed in the matrix and also increase with the degree of irradiation. These variations were interpreted as the effect of matrix hardness in the precipitate structure and how this affects the distribution of the misfit strain tensor between precipitate and matrix.

The huge strain anisotropy observed for the $\delta$-hydride peaks width is a manifestation of the mechanical elastic anisotropy of this phase, being very soft and ductile for directions on the close packed planes, in agreement with ab-initio simulations presented in the literature. 


\section{Acknowledgments}

This research was partially funded by CONICET under PIP-542-2011, and by IAEA under Research Contract 17252 "Kinetics of hydride precipitation under applied stresses on Zrbased alloys" which form part of the CRP F12024 entitled "Utilisation of accelerator-based real-time and in-situ methods in investigation of materials for energy applications: CRP code: F12024". Usage of the Advanced Photon Source was supported by the U.S. Department of Energy, under Contract No. DE-AC02-06CH11357. G.R is grateful for the partial support of the French State through the program "Investment in the future" operated by the National Research Agency (ANR) and referenced by ANR-11-LABX-0008-01, LabEx-DAMAS. 


\section{References}

[1] J.-H. Huang, S.-P. Huang,C.-S. He, The ductile-brittle transition of a Zirconium alloy due to Hydrogen, Scr. Metall. et Mater. 28 (1993) 1537-1542.

[2] J.B. Bai, C. Prioul, S. Lansiart, D. François, Brittle fracture induced by hydrides in zircaloy-4, Scr. Metall. et Mater. 25, (1991) 2559-2563.

[3] In "Materials' ageing and degradation in light water reactors, Mechanisms and management”, Ed. K.L. Murty, Woodhead Publishing Limited, 2013, page 52.

[4] M.P. Puls, The influence of hydride size and matrix strength on fracture initiation at hydrides in zirconium alloys, Metall. Trans. A 19A, (1988) 1507-1522.

[5] C. J. Simpson, C.E. Ells, Delayed hydrogen embrittlement of Zr-2.5wt.\%Nb, J. Nucl. Mater. 52 (1974) 289-295.

[6] R. Dutton, M.P. Puls, A theoretical Model for Hydrogen Induced Sub Critical Crack Growth", in Effect of Hydrogen on Behavior of Materials, A.W. Thomson and I. M . Bernstein, Eds. TMS-AIME, New York, NY, (1976) 512.

[7] E. Zuzek, J.P. Abriata, A. San Martin, F. D. Manchester, The H-Zr (HydrogenZirconium) System, Bull. Alloy Phase Diagrams Vol 11 Nr 4 (1990) 385-386.

[8] V. Perovic, G.C. Weatherly, C.J. Simpson, Hydride precipitation in $\alpha / \beta$ zirconium alloys, Acta Metall. 31 (1983) 1381-1391.

[9] S. S. Sidhu, N.S.S. Murthy,F.P. Campos, Neutron and X-ray diffraction studies of nonstoichiometric metal hydrides, Adv. Chem. Ser. 39, (1963) 87-98.

[10] K.E. Moore, W.A.Young, Phase studies of the Zr-H system at high hydrogen concentrations, J. Nucl. Mater. 27, (1968) 316-324.

[11] K.G. Barraclough, C.J. Beevers, Some observations of the phase transformations in zirconium hydrides, J. Nucl. Mater. 34, (1970) 125-134.

[12] R.C. Jr. Bowman, B.D. Clark, Effects of thermal treatments on lattice properties and electronic structure of ZrH, Phys. Rev. B31, (1985) 5604-5615. 
[13] M. P. Puls, in "The Effect of Hydrogen and Hydrides on the Integrity of Zirconium Alloy Components: Delayed Hydride Cracking”, Ed. Springer-Verlag London 2012.

[14] R.L. Beck, W. M. Mueller, Mechanical properties of solid zirconium hydride. In: Nuclear Metallurgy. Metall. Soc. AIME III, (1960) 63-66 .

[15] K.G. Barraclough, C.J. Beevers, Some observations on the deformation characteristics of bulk polycrystalline zirconium hydrides. Part I: The deformation and fracture of hydrides based on the d-phase, J. Mater. Sci. 4, (1969) 518-525.

[16] S. Yamanaka, K. Yoshioka, M. Uno, M Katsura, H Anada, T Matsuda, S Kobayashi, Thermal and mechanical properties of zirconium hydride. J. Alloys Compd 293-295, (1999) 23-29.

[17] N. Oono, R. Kasada, T. Higuchi, K. Sakamoto, M. Nakatsuka, A. Hasegawa, S. Kondo, H. Matsui, A. Kimura, Irradiation hardening and microstructure evolution of ionirradiated Zr-hydride, J. Nucl. Mat., vol. 419, no. 1-3, (2011) 366-370.

[18] M.P. Puls, S.Q. Shi, J. Rabier, Experimental studies of mechanical properties of solid zirconium hydrides, J. Nucl. Mater. 336, (2005) 73-80.

[19] N. Oono, R. Kasada, T. Higuchi, K. Sakamoto, M. Nakatsuka, A. Hasegawa, S. Kondo, N. Y. Iwata, H. Matsui, A. Kimura, Comparison of irradiation hardening and microstructure evolution in ion-irradiated delta and epsilon hydrides, J.1 of Nucl.

Mat., vol. 442, no. 1-3, Supplement 1, (2013) S826-S829.

[20] M. Kerr, M.R. Daymond, R.A. Holt, J.D. Almer, Strain evolution of zirconium hydride embedded in a Zircaloy-2 matrix, J. Nucl. Mat., Vol 380,( 2008) 70-75.

[21] A. Steuwer, J.R. Santisteban, M. Preuss, M.J. Peel, T. Buslaps, M. Harada, Evidence of stress-induced hydrogen ordering in zirconium hydrides, Acta Mater.Vol 57, (2009) $145-152$. 
[22] M. Kerr, M.R. Daymond, R.A. Holt, J.D. Almer, S. Stafford, Observation of growth of a precipitate at a stress concentration by synchrotron X-ray diffraction, Scrip. Mater. Vol 62 (2010) 341-344.

[23] M. Kerr, M.R. Daymond, R.A. Holt, J.D. Almer, S. Stafford, K.B. Colas, Fracture of a minority phase at a stress concentration observed with synchrotron X-ray diffraction, Scrip. Mater., Vol. 61(2009) 939-942.

[24] J. B. Bai, C. Prioul, D. François, Hydride embrittlement in ZIRCALOY-4 plate: Part I. Influence of microstructure on the hydride embrittlement in ZIRCALOY-4 at $20{ }^{\circ} \mathrm{C}$ and $350{ }^{\circ} \mathrm{C}$, MMTA, vol. 25, no. 6, (1994) 1185-1197.

[25] Z. Wang, U. Garbe, H. Li, Y. Wang, A. J. Studer, Gu.Sun, R. P. Harrison, X. Liao, M. A. Vicente Alvarez, J. R. Santisteban, C. Kong, Microstructure and texture analysis of $\delta$ hydride precipitation in Zircaloy-4 materials by electron microscopy and neutron diffraction, J. Appl. Cryst. 47 (2014), 303-315.

[26] G. Ribárik, T. Ungár, Characterization of the microstructure in random and textured polycrystals and single crystals by diffraction line profile analysis, Mater. Sci. Eng. A528, (2010) 112-121.

[27] G. Ribárik, B. Joni, T. Ungár, in preparation.

[28] M.A. Vicente Alvarez, J.R. Santisteban, G. Domizzi, J. Almer, Phase and texture analysis of a hydride blister in a $\mathrm{Zr}-2.5 \% \mathrm{Nb}$ tube by synchrotron $\mathrm{X}$-ray diffraction, Acta Mater. 59, (2011) 2210-2220.

[29] G. Domizzi , R.A. Enrique, J. Ovejero-Garcia, G.C. Buscaglia, Blister growth in zirconium alloys: experimentation and modeling. J Nucl Mater Vol 229 (1996) 36-47.

[30] R. L Snyder, J. Fiala, H. J. Bunge, in "Defect and microstructure analysis by diffraction", International Union of Crystallography, Oxford Science Publications, Oxford, UK, 1999. 
[31] M. Griffiths, D. Sage, R.A. Holt, C.N. Tome, Determination of Dislocation Densities in HCP Metals from X-ray Diffraction Line-Broadening Analysis, Metal and Mater Trans A, Vol 33A, (2002) 859-865.

[32] J.E. Winegar, AECL Technical Report CRNL-4098 (1987).

[33] L. Balogh, D. W. Brown, P. Mosbrucker, F. Long, M. R. Daymond, Dislocation structure evolution induced by irradiation and plastic deformation in the $\mathrm{Zr}-2.5 \mathrm{Nb}$ nuclear structural material determined by neutron diffraction line profile analysis, Acta Mater. Vol 60, (2012) 5567-5577.

[34] B.E. Warren, in Chapter 13 of "X-Ray Diffraction”'Dover Publications, Inc. NY, First Edition 1990.

[35] P. Scherrer, N. G. W. Gessell, 98 (1918), Zsigmondy's Kolloidchemie, $3^{\text {rd }}$ Ed, 394.

[36] G. K. Williamson and W. H. Hall, X-ray line broadening from filed aluminium and wolfram, Acta Metall. 1 (1953) 22-31.

[37] M.A. Vicente Alvarez, J.R. Santisteban,P. Vizcaino, A.V. Flores, A.D. Banchik, J. Almer, Hydride reorientation in $\mathrm{Zr} 2.5 \mathrm{Nb}$ studied by synchrotron X-Ray diffraction, Acta Mater. 60 (2012), 6892-6906.

[38] A.T.W. Barrow, A. Korinek, M.R. Daymond, Evaluating zirconium-zirconium hydride interfacial strains by nano-beam electron diffraction, J. Nucl. Mat. Vol. 432 (2013) $366-370$.

[39] T. Ungár, I. Dragomir, Á. Révész, A. Borbély, The contrast factors of dislocations in cubic crystals: the dislocation model of strain anisotropy in practice, J. Appl. Cryst. 32 (1999) 992-1002.

[40] J.P. Giroldi, P. Vizcaíno, A.V. Flores, A.D. Banchik, Hydrogen terminal solid solubility determinations in $\mathrm{Zr}-2.5 \mathrm{Nb}$ pressure tube microstructure in an extended concentration range, J. Alloy Compd 474 (2009) 140-146. 
[41] B. W. Leitch, M. P. Puls, Finite element calculation of the accommodation energy of a misfitting precipitate in an elastic-plastic matrix, Metall and Mater Trans A, Vol 23A, (1992) 797-806.

[42] M.A. Meyers, K K. Chawla, in "Mechanical Metallurgy, Principles and applications", Prentice-Hall Inc. Englewoo Cliffs, New Yersey, (1984), page 57.

[43] P.A.T. Olsson, A.R. Massih, J. Blomqvist, A.-M. Alvarez Holston, C. Bjerkén, Ab initio thermodynamics of zirconium hydrides and deuterides, Comp. Mat. Sci. 86 (2014) $211-222$

[44] W. Zhu, R. Wang, G. Shu, P. Wu, H. Xiao, First-Principles Study of Different Polymorphs of Crystalline Zirconium Hydride, J. Phys. Chem. C 114 (2010) 2236122368. 


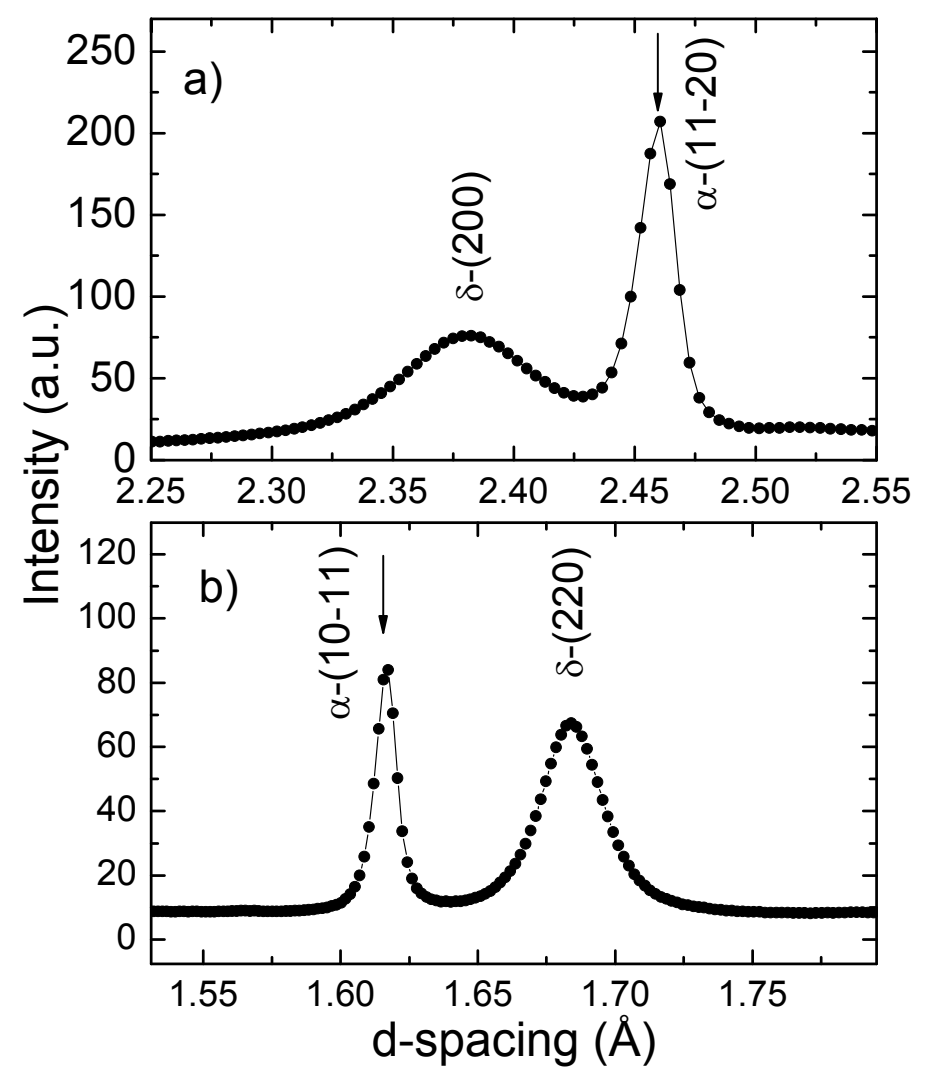

Figure 1: Details of two sections of the diffractogram measured in the blister along line $\mathrm{X}$ at a distance $\mathrm{x}=1.5$ from the center. Peaks of both $\delta$-hydride and $\alpha-\mathrm{Zr}$ are compared. 


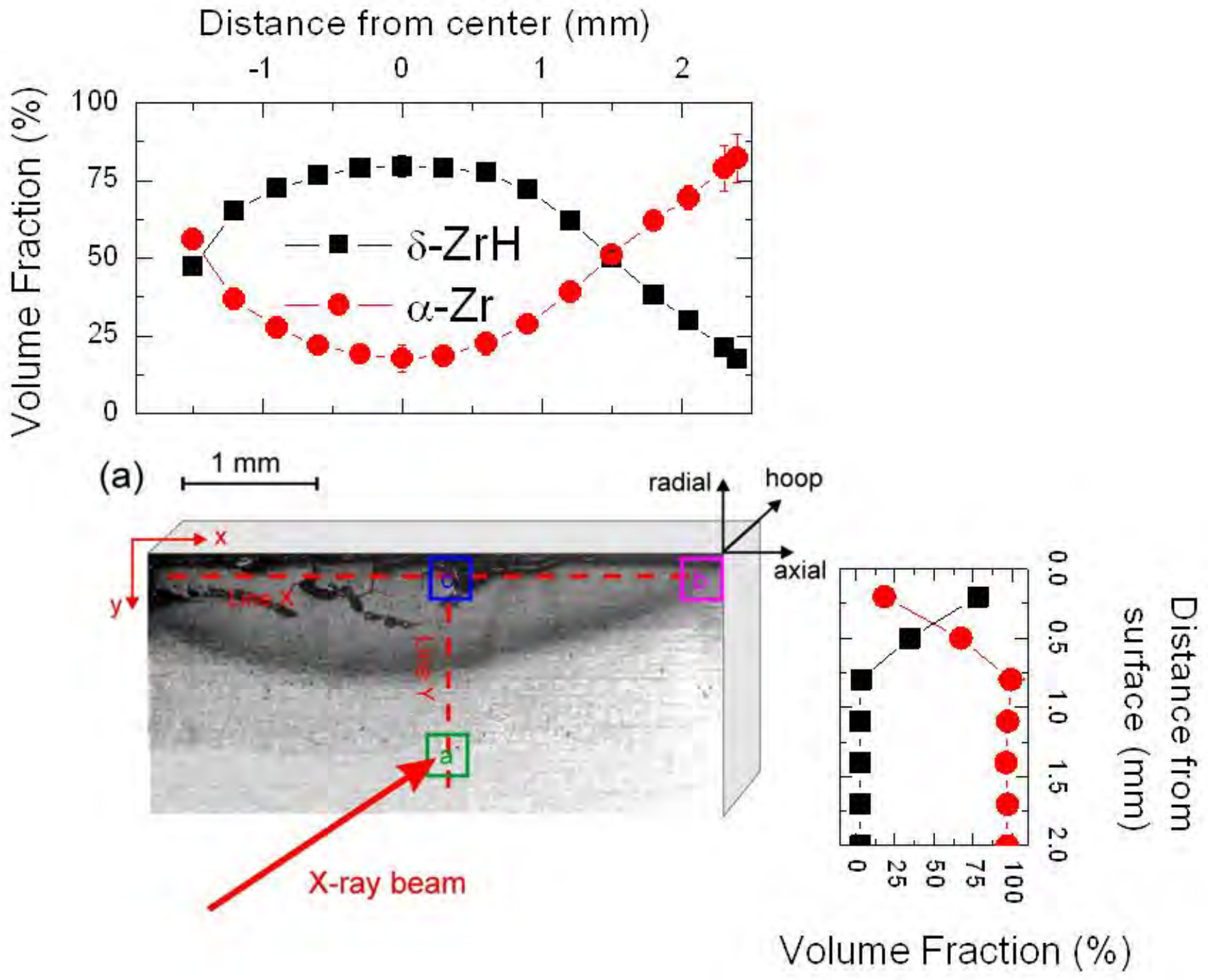

Figure 2: Experimental setup for the blister sample, the $\mathrm{X}$ ray beam impacts alog the hoop direction of the pressure tube. Images of the Debye-Scherrer rings are collected by a CCD detector placed behind the sample at different points within the blister as indicated by the squares along line $\mathrm{X}$ and line $\mathrm{Y}$. The $\delta$-hydride and $\alpha \mathrm{Zr}$ volume fractions are shown along these two lines. 


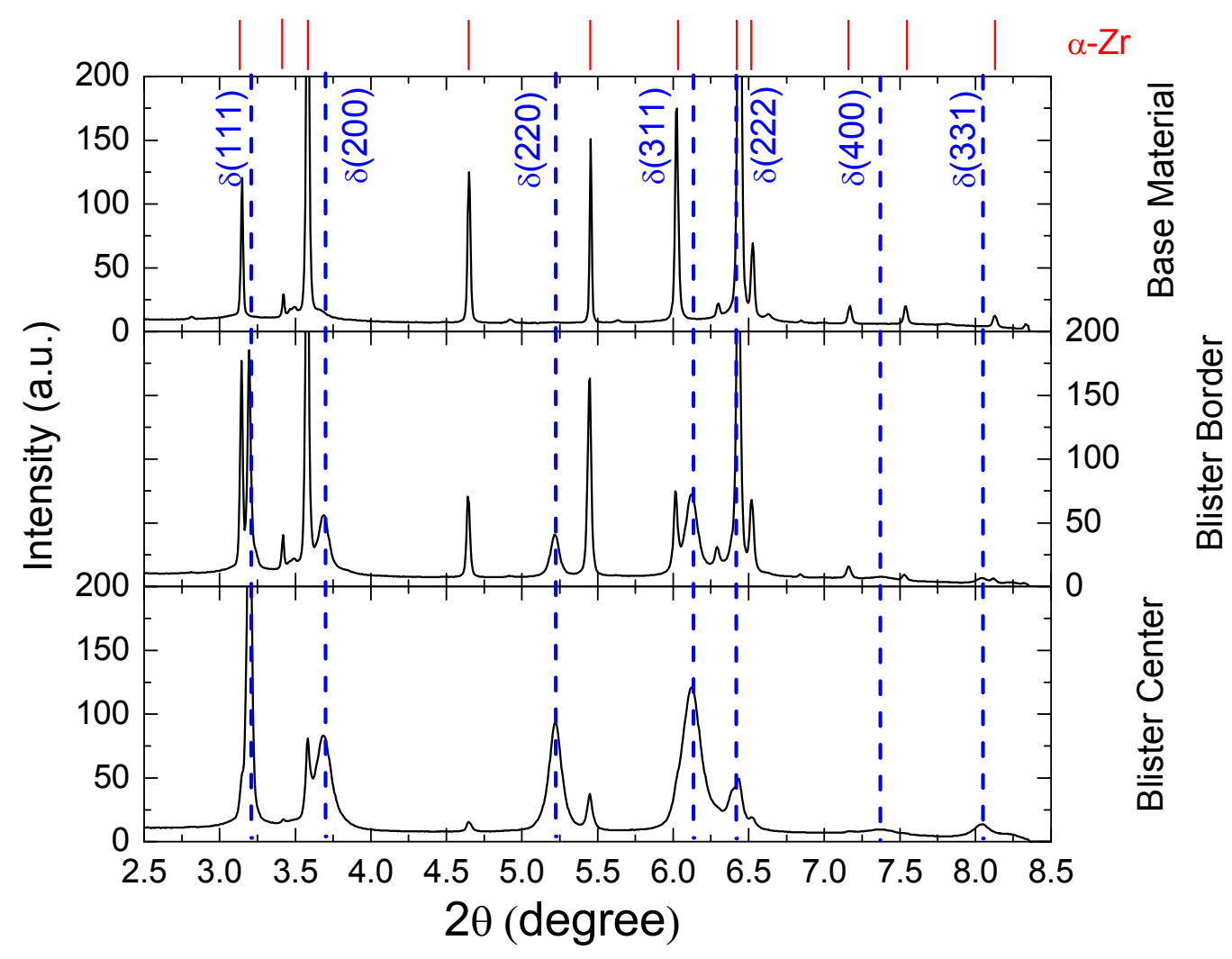

Figure 3: $\theta-2 \theta$ diffractograms at three positions in the blister along line $Y$, hydride peaks are indicated by the vertical dashed blue lines. The angular position of the $\alpha \mathrm{Zr}$ peaks are indicated by the red lines at the top of the figure. At the center of the blister, up to 7 peaks of $\delta$ hydride phase are well resolved. 

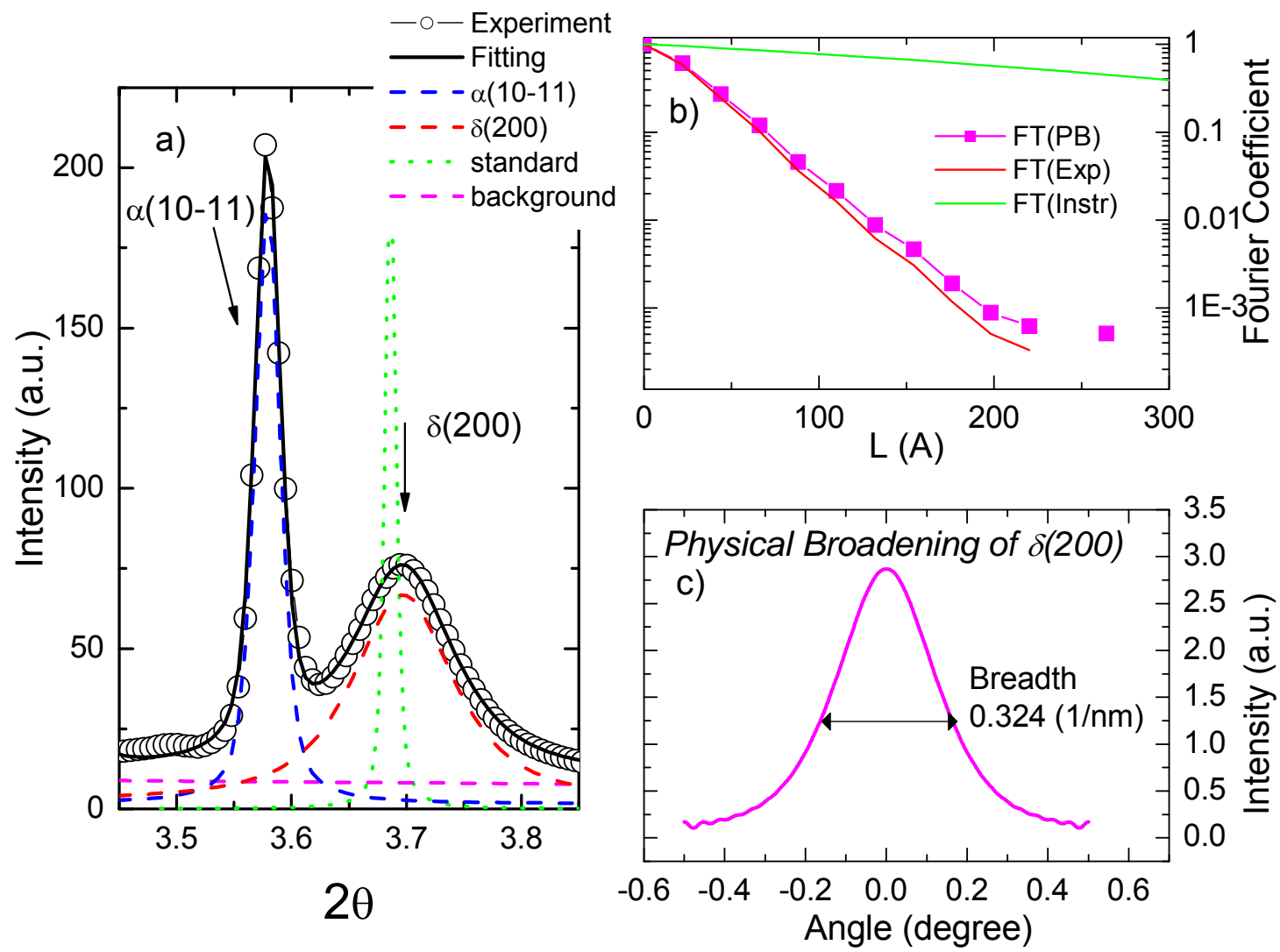

Figure 4: Procedure used to obtain physical broadening from the experimental peaks. a) comparison between the experimental points (hollow circles) and fitting (solid black lines) considering the contribution of the diffraction peaks as pseudo-Voigt functions (blue dashed line for $\alpha(10-10)$ and red dashed line for $\delta(200))$ and a linear background (dashed magenta). The dashed green line shows an extrapolation of the diffraction peak expected for a standard sample (instrumental broadening) for this angular range. b) Fourier coefficients of the stardard sample (FT(Instr)), of the fitted pseudo-Voigt function for $\delta(200)$ FT(Exp) , and the resulting values for the physical brosening after deconvolution FT(PB). c) Physical broadening function of $\delta(200)$ peak obtained from the Fourier coefficients FT(PB) shown in b). 


\begin{tabular}{|c|c|c|c|c|c|c|}
\hline Sample & $\begin{array}{c}\text { XRD } \\
\text { Facility }\end{array}$ & Sn & Fe & Cr & Nb & $\begin{array}{c}\text { Impurities } \\
\text { (wppm) }\end{array}$ \\
\hline PT - Blister & $\begin{array}{c}\text { APS-ANL- } \\
\text { USA }\end{array}$ & & & & 2.5 & \\
\hline $\begin{array}{c}\text { Zircaloy-4 } \\
\text { Unirradiated } \\
\text { (Zry-H260) }\end{array}$ & $\begin{array}{c}\text { LNLS } \\
\text { Brasil }\end{array}$ & 1.49 & 0.2 & 0.11 & & $\begin{array}{c}\mathrm{O}<1100 \\
\mathrm{Ni}<49 \\
\mathrm{Hf}<100\end{array}$ \\
\hline $\begin{array}{c}\text { Zircaloy-4 } \\
\text { Irradiated } \\
\text { Zry-IR) }\end{array}$ & $\begin{array}{c}\text { LNLS- } \\
\text { Brasil }\end{array}$ & 1.6 & 0.22 & 0.065 & & $\mathrm{Ni}<32$ \\
\hline
\end{tabular}

Table 1: Chemical composition of the $\mathrm{Zr}$ alloys before $\mathrm{H}$ charging. The XRD facility where measurement was done is also indicated. 


\begin{tabular}{|c|c|c|c|c|c|c|c|c|c|}
\hline \multicolumn{2}{|c|}{ Sample } & $\begin{array}{l}\text { H content } \\
(\mathrm{ppm})\end{array}$ & $(111)$ & $(200)$ & $(220)$ & (311) & $(222)$ & $(400)$ & (331) \\
\hline & & & \multicolumn{7}{|c|}{$\mathrm{K}(1 / \mathrm{nm})$} \\
\hline & & & 3.629 & 4.197 & 5.94 & 6.942 & 7.259 & 8.393 & 9.137 \\
\hline & & & \multicolumn{7}{|c|}{ Integral breadth $(\Delta \mathrm{K})(1 / \mathrm{nm})$} \\
\hline \multirow{16}{*}{ 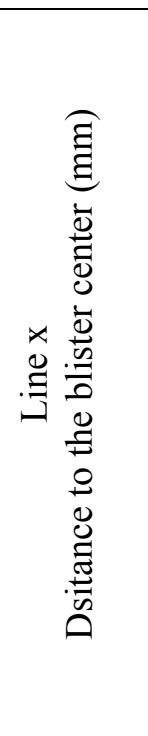 } & 2.4 & $3200+-300$ & 0.048 & 0.184 & 0.161 & 0.238 & 0.095 & 0.350 & 0.226 \\
\hline & 2.3 & $3800+-360$ & 0.047 & 0.214 & 0.180 & 0.265 & 0.103 & 0.382 & 0.238 \\
\hline & 2.05 & $5400+-408$ & 0.048 & 0.191 & 0.166 & 0.245 & 0.098 & 0.355 & 0.227 \\
\hline & 1.8 & $7000+-300$ & 0.055 & 0.245 & 0.196 & 0.289 & 0.113 & 0.403 & 0.258 \\
\hline & 1.5 & $9100+-450$ & 0.060 & 0.282 & 0.217 & 0.321 & 0.123 & 0.445 & 0.286 \\
\hline & 1.2 & $11300+-530$ & 0.064 & 0.324 & 0.234 & 0.349 & 0.133 & 0.493 & 0.306 \\
\hline & 0.9 & $13100+-500$ & 0.068 & 0.354 & 0.253 & 0.369 & 0.140 & 0.524 & 0.335 \\
\hline & 0.6 & $14100+-350$ & 0.071 & 0.360 & 0.270 & 0.381 & 0.142 & 0.521 & 0.358 \\
\hline & 0.3 & $14500+-600$ & 0.073 & 0.345 & 0.285 & 0.383 & 0.140 & 0.562 & 0.373 \\
\hline & 0 & $14500+-600$ & 0.075 & 0.331 & 0.293 & 0.377 & 0.132 & 0.560 & 0.374 \\
\hline & -0.3 & $14400+-530$ & 0.074 & 0.322 & 0.297 & 0.374 & 0.128 & 0.560 & 0.372 \\
\hline & -0.6 & $14000+-300$ & 0.073 & 0.312 & 0.292 & 0.369 & 0.126 & 0.491 & 0.361 \\
\hline & -0.9 & $13200+-360$ & 0.063 & 0.293 & 0.279 & 0.364 & 0.126 & 0.497 & 0.341 \\
\hline & -1.2 & $11900+-400$ & 0.057 & 0.275 & 0.255 & 0.347 & 0.118 & 0.448 & 0.308 \\
\hline & -1.5 & $8600+-450$ & 0.053 & 0.242 & 0.223 & 0.311 & 0.105 & 0.410 & 0.266 \\
\hline & 2.4 & $7300+-350$ & 0.052 & 0.216 & 0.205 & 0.297 & 0.105 & 0.505 & 0.252 \\
\hline \multirow{4}{*}{ 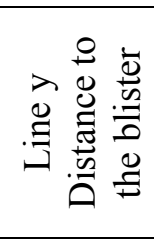 } & 0 & $14500+-600$ & 0.075 & 0.331 & 0.293 & 0.377 & 0.132 & 0.560 & 0.374 \\
\hline & -0.3 & $\sim 450$ & 0.063 & 0.293 & 0.211 & 0.315 & - & 0.46 & - \\
\hline & -0.6 & $\sim 250$ & 0.045 & 0.20 & 0.15 & 0.2 & - & 0.40 & - \\
\hline & -0.9 & $\sim 200$ & 0.04 & 0.20 & 0.17 & - & - & - & - \\
\hline \multicolumn{2}{|c|}{ Zry-H260 } & 260 & $\begin{array}{c}0.049 \\
\pm 0.005\end{array}$ & $\begin{array}{c}0.19 \\
\pm 0.02\end{array}$ & $\begin{array}{l}0.137 \\
\pm 0.01\end{array}$ & $\begin{array}{c}0.16 \\
\pm 0.02 \\
\end{array}$ & $\begin{array}{l}0.062 \\
\pm 0.01\end{array}$ & - & $\begin{array}{l}0.222 \\
\pm 0.05 \\
\end{array}$ \\
\hline \multicolumn{2}{|l|}{ Zry-IR } & $140 *$ & $\begin{array}{c}0.0696 \\
\pm 0.01\end{array}$ & - & $\begin{array}{l}0.279 \\
\pm 0.05\end{array}$ & - & $\begin{array}{c}0.12 \\
\pm 0.03\end{array}$ & - & - \\
\hline \multicolumn{2}{|c|}{ Zry-IR-600-24hrs } & $140 *$ & $\begin{array}{c}0.049 \\
\pm 0.009 \\
\end{array}$ & $\begin{array}{l}0.178 \\
\pm 0.05 \\
\end{array}$ & $\begin{array}{l}0.1309 \\
\pm 0.009 \\
\end{array}$ & - & $\begin{array}{c}0.08 \\
\pm 0.02 \\
\end{array}$ & - & $\begin{array}{l}0.234 \\
\pm 0.02 \\
\end{array}$ \\
\hline \multicolumn{2}{|c|}{ Zry-IR-400-72hrs } & $140 *$ & $\begin{array}{c}0.064 \\
\pm 0.003 \\
\end{array}$ & - & $\begin{array}{c}0.191 \\
\pm 0.008 \\
\end{array}$ & - & $\begin{array}{c}0.068 \pm \\
0.017 \\
\end{array}$ & - & $\begin{array}{c}0.23 \\
\pm 0.09 \\
\end{array}$ \\
\hline
\end{tabular}

*Deuterium

Table 2:Integral breadths of the physical broadening function for hydride peaks, obtained after deconvolution with the procedure described in Figure 4. Results of hydrides formed in different Zirconium alloys, grown under different conditions and measured in different instruments, are compared. 


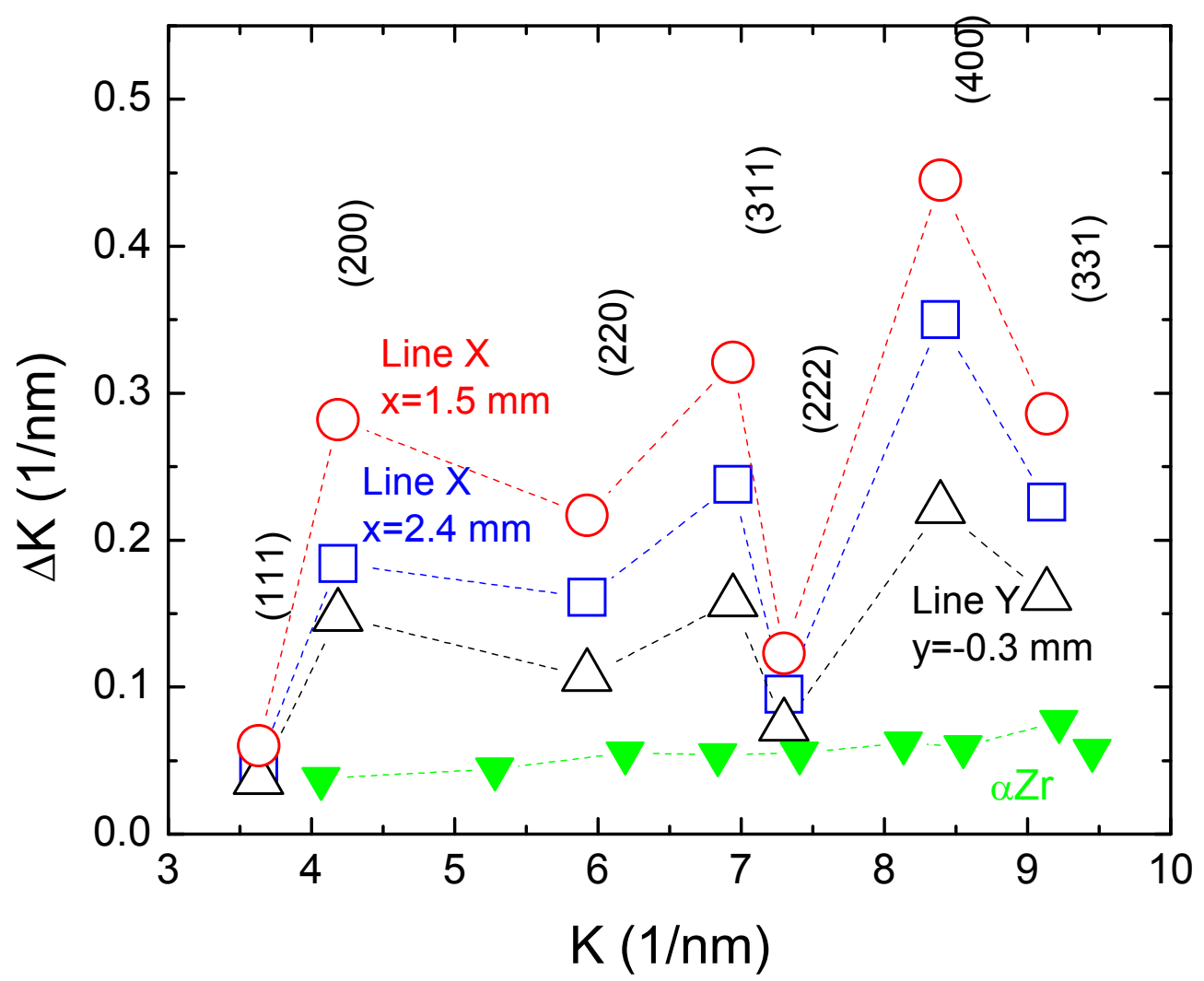

Figure 5: Physical line broadening $\Delta \mathrm{K}$ of the most intense $\delta$ hydride peaks for different $\mathrm{H}$ contents for Zrly-4 and for different points in the blister grown in the pressure tube. Peak widths of $\alpha \mathrm{Zr}$ are included for comparison. 


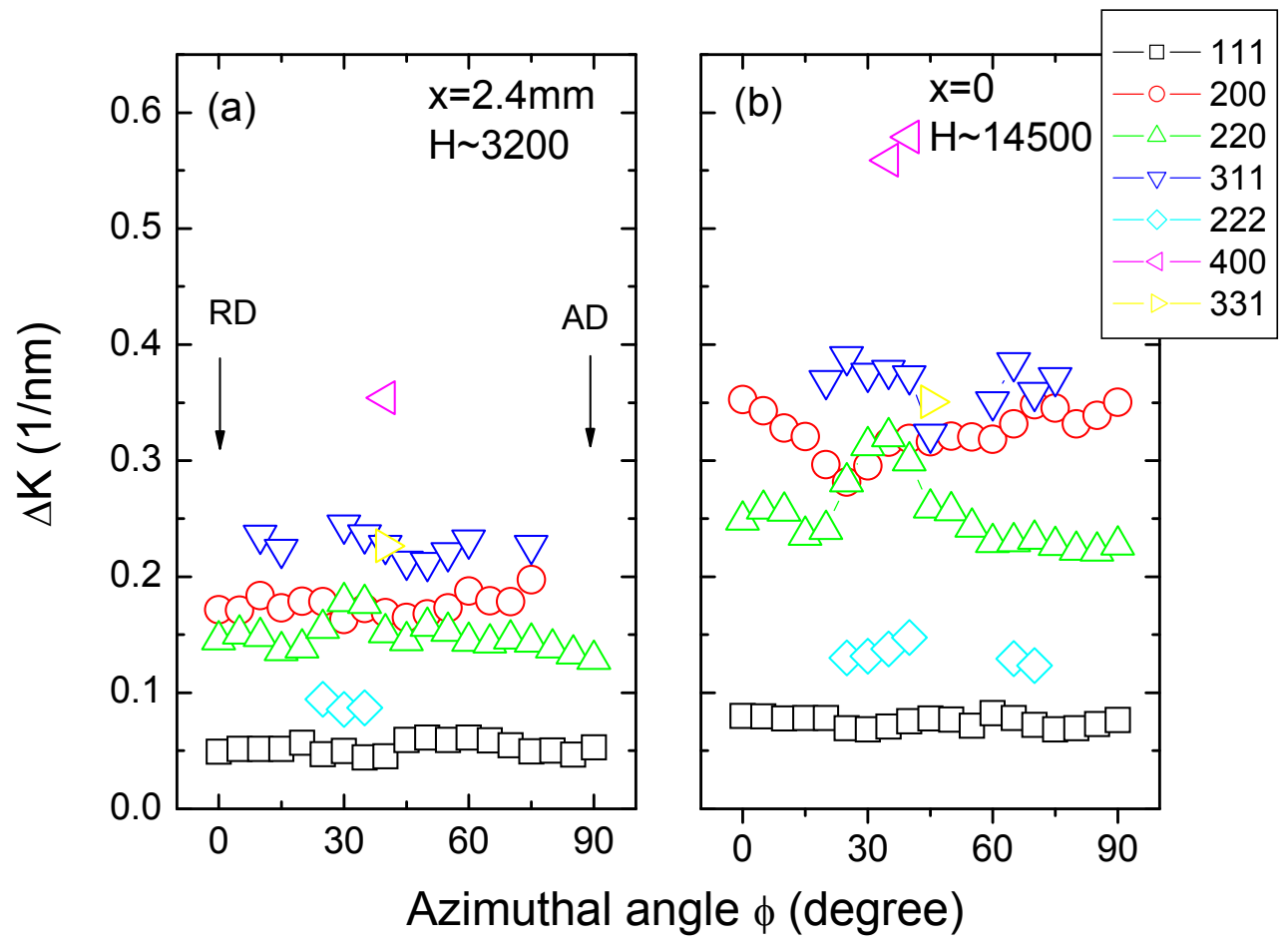

Figure 6: Angular dependence along the Debye ring of integral breadth $\Delta \mathrm{K}$ for $\delta$-hydride peaks measured at two locations in the blister along Line $\mathrm{X}$. 

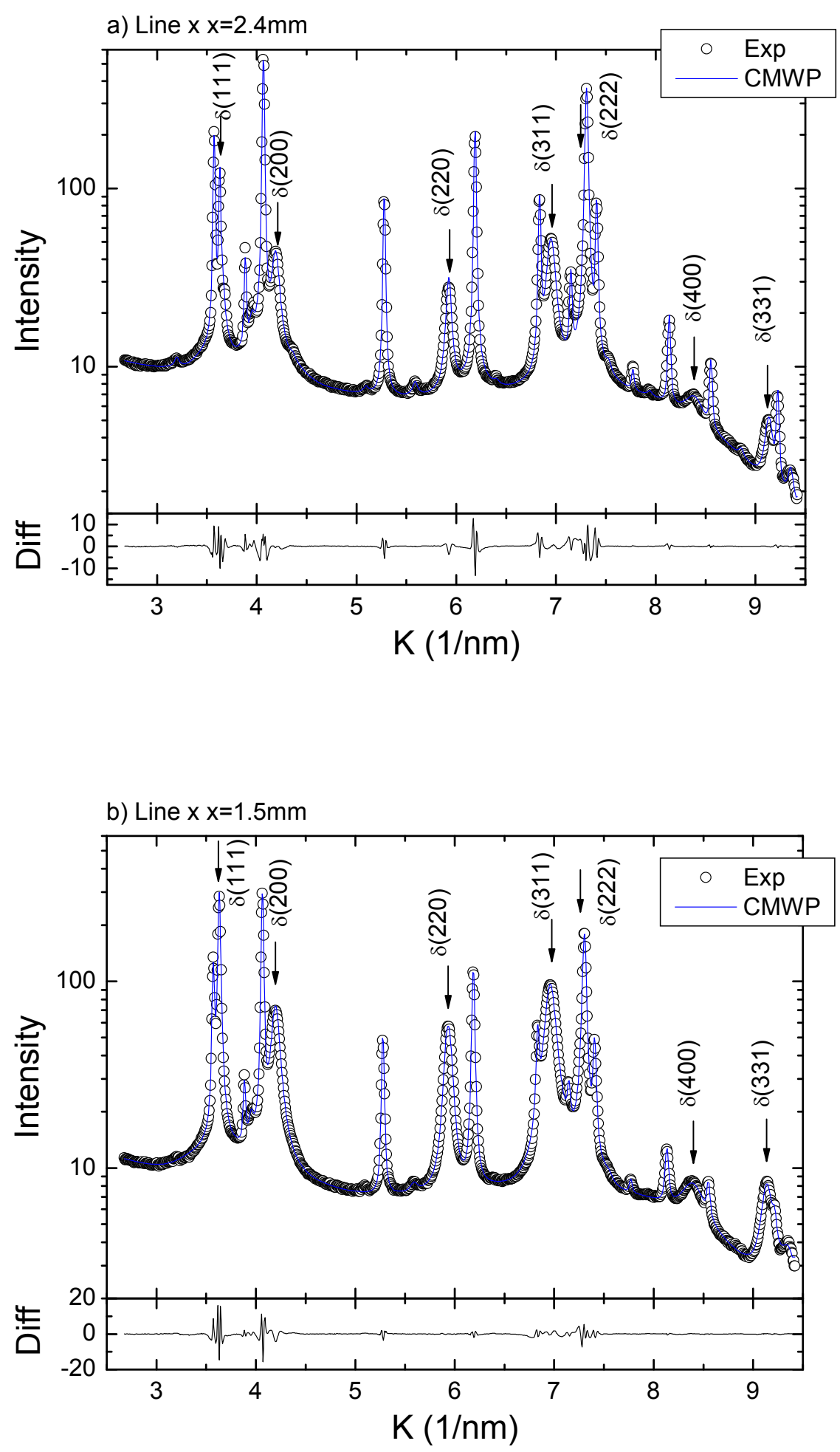

Figure 7: Comparison between experimental diffractograms (points) and CMWP simulations (blue line) for two position along Line $X$ (in log scale). The difference between the curves is plotted at the bottom of the figures in linear scale. 


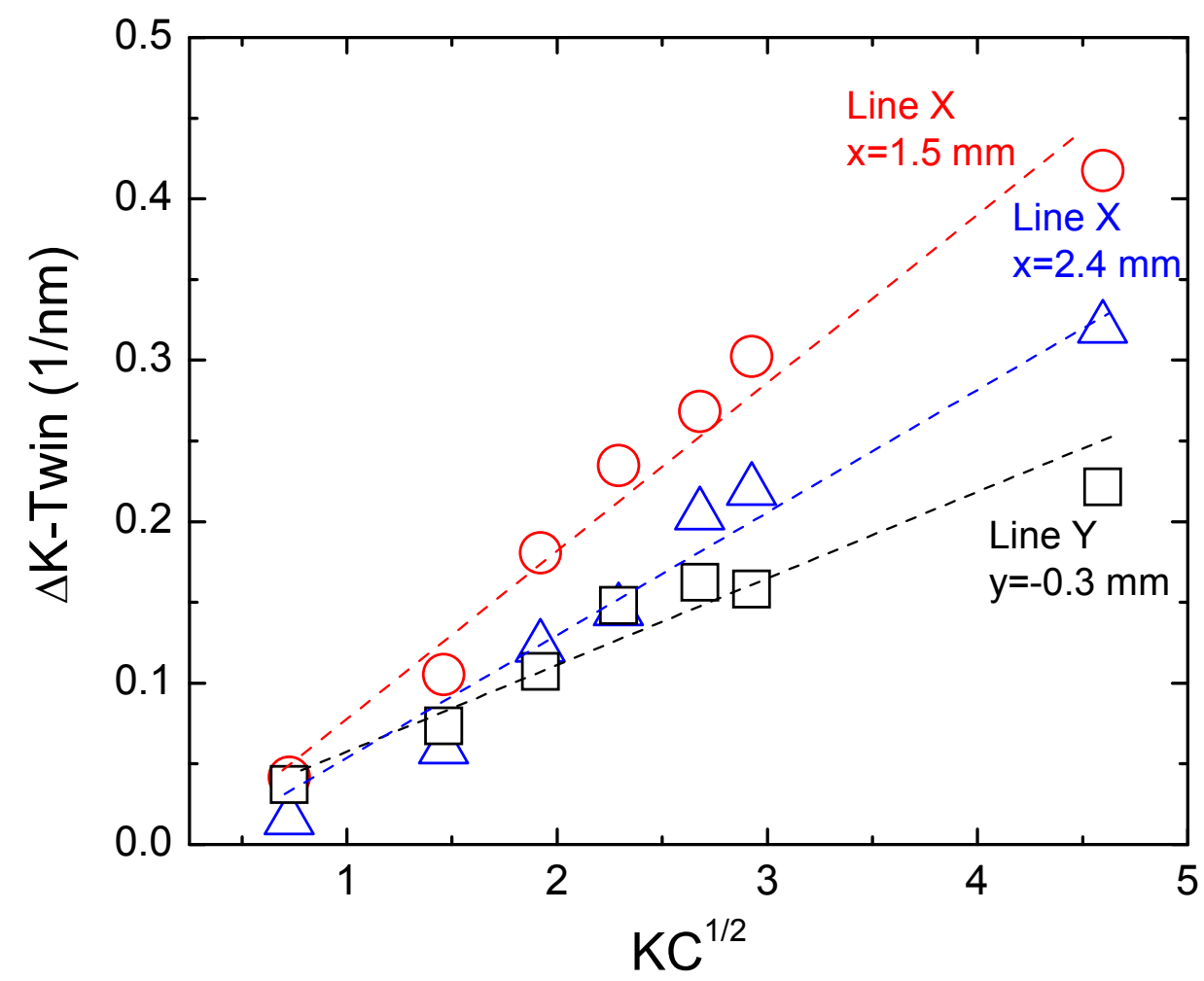

Figure 8: Modified Williamson-Hall plot for three positions along the blister sample. The y-axis shows integral breadth after sustraction of the contribution due to planar defects (twinning, stacking faults, etc.). In this type of plot, points are aligned following a linear dependence being the slope of the line proportional to the dislocation density and the value at $\mathrm{y}=0$ proportional to the inverse of the particle size. 


\begin{tabular}{|c|c|c|c|c|c|c|c|c|c|}
\hline \multicolumn{2}{|l|}{ Sample } & H content & \multicolumn{5}{|c|}{$\delta-\mathrm{ZrH}$} & \multicolumn{2}{|c|}{$\alpha-Z r$} \\
\hline & & & $\begin{array}{c}\rho\left(1 / \mathrm{m}^{2}\right) \\
\left(10^{14}\right)\end{array}$ & $\beta(\%)$ & $\begin{array}{l}d_{\text {Twin }} \\
{[n \text { n] }}\end{array}$ & $\begin{array}{c}\langle x\rangle_{\text {area }} \\
{[\mathrm{nm}]}\end{array}$ & $q$ & $\begin{array}{c}\rho\left(1 / \mathrm{m}^{2}\right) \\
\left(10^{14}\right)\end{array}$ & $\begin{array}{c}\langle x\rangle_{\text {area }} \\
{[\mathrm{nm}]}\end{array}$ \\
\hline \multirow{7}{*}{ 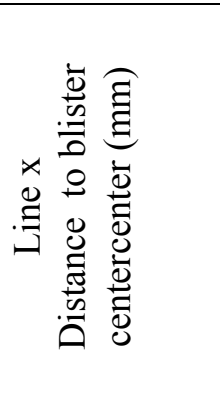 } & 2.4 & $3200 \pm 300$ & 94 & 1.8 & 15 & 68 & 2.9 & 0.8 & 74 \\
\hline & 2.05 & $5400 \pm 408$ & 86 & 0.85 & 32 & 75 & 2.9 & 1.3 & 93 \\
\hline & 1.5 & $9100 \pm 450$ & 150 & 1.8 & 15 & 135 & 2.5 & 1.6 & 49 \\
\hline & 0.6 & $14100 \pm 350$ & 330 & 0.95 & 29 & 210 & 2.51 & 11 & 33 \\
\hline & 0 & $14500 \pm 600$ & 280 & 1.5 & 18 & 93 & 2.45 & 32 & 23 \\
\hline & -0.9 & $13200 \pm 360$ & 216 & 1.5 & 18 & 134 & 2.53 & 34 & 52 \\
\hline & -2.4 & $7300 \pm 350$ & 170 & 2.1 & 13 & 93 & 2.5 & 5.9 & 65 \\
\hline \multirow{5}{*}{ 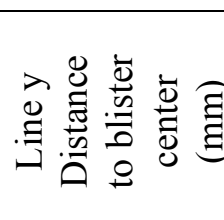 } & & & & & & & & & \\
\hline & 0 & $14500 \pm 600$ & 387 & 2.1 & 13 & 38 & 2.6 & 16.1 & 31 \\
\hline & 0.3 & $\sim 450$ & 184 & 2.5 & 11 & 98 & 2.7 & 1.3 & 78 \\
\hline & 0.6 & $\sim 250$ & 25 & $* *$ & $* *$ & 12 & 2.5 & 1.1 & 173 \\
\hline & 0.9 & $\sim 200$ & 24 & $* *$ & $* *$ & 8.1 & 2.5 & 1.4 & 296 \\
\hline \multicolumn{2}{|l|}{ Zry-H260 } & 260 & 54 & 2.5 & 11 & 275 & 2.9 & 0.14 & $>2000$ \\
\hline \multicolumn{2}{|l|}{ Zry-IR } & & 132 & 9 & 4 & 180 & 2.5 & 51 & 115 \\
\hline \multicolumn{2}{|c|}{ Zry-IR-600-24hrs } & $140^{*}$ & 45 & 1.8 & 15 & 680 & 2.9 & 0.05 & $>2000$ \\
\hline \multicolumn{2}{|c|}{ Zry-IR-400-72hrs } & & 75 & 0.75 & 37 & 220 & 2.9 & 1.4 & $>2000$ \\
\hline
\end{tabular}

*Deuterium

** could not be estimated

Table 3: Main microstuctural variables of hydride and $\alpha$ phases obtained from the experimental diffractograms after fitting with CMWP . 


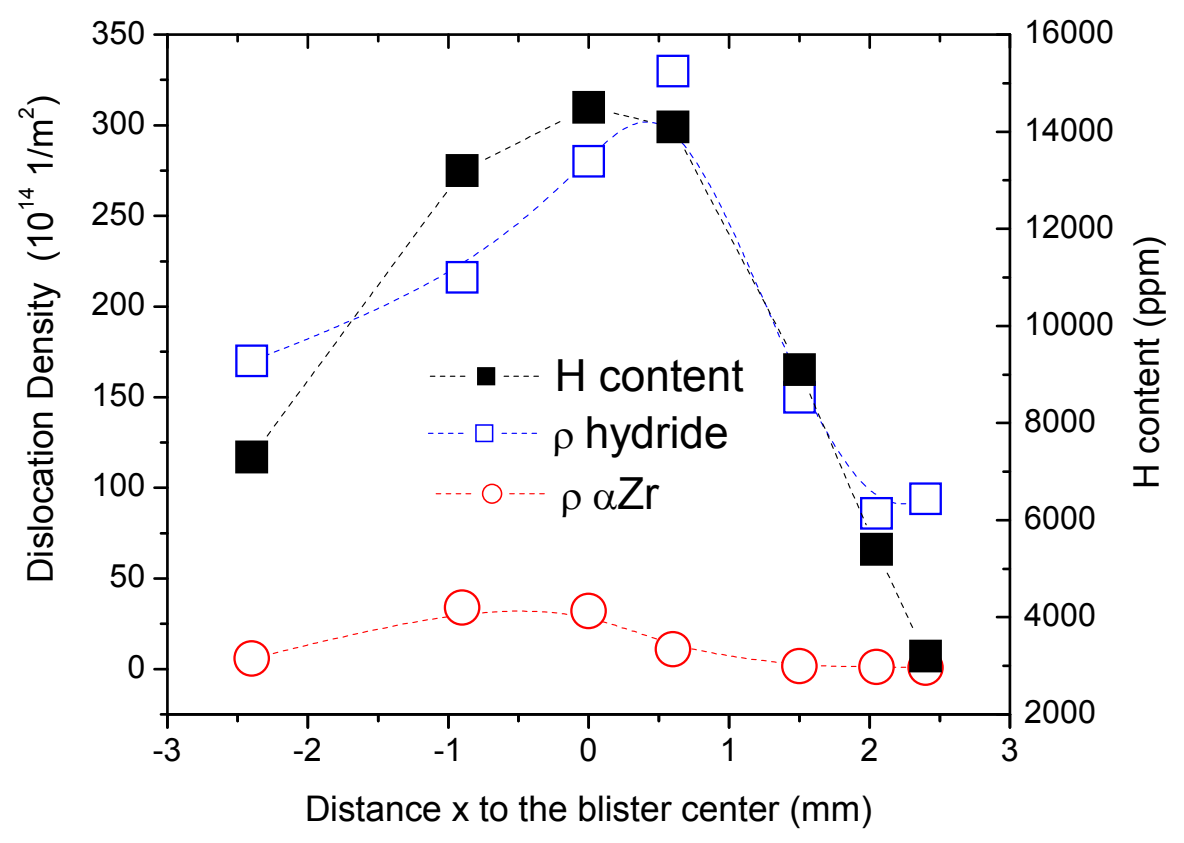

Figure 9: Dislocation densities of $\delta$ hydrde (blue points) and $\alpha \mathrm{Zr}$ (red points) along Line $\mathrm{X}$ in the blister sample. H content is superimposed as black points for comparison 


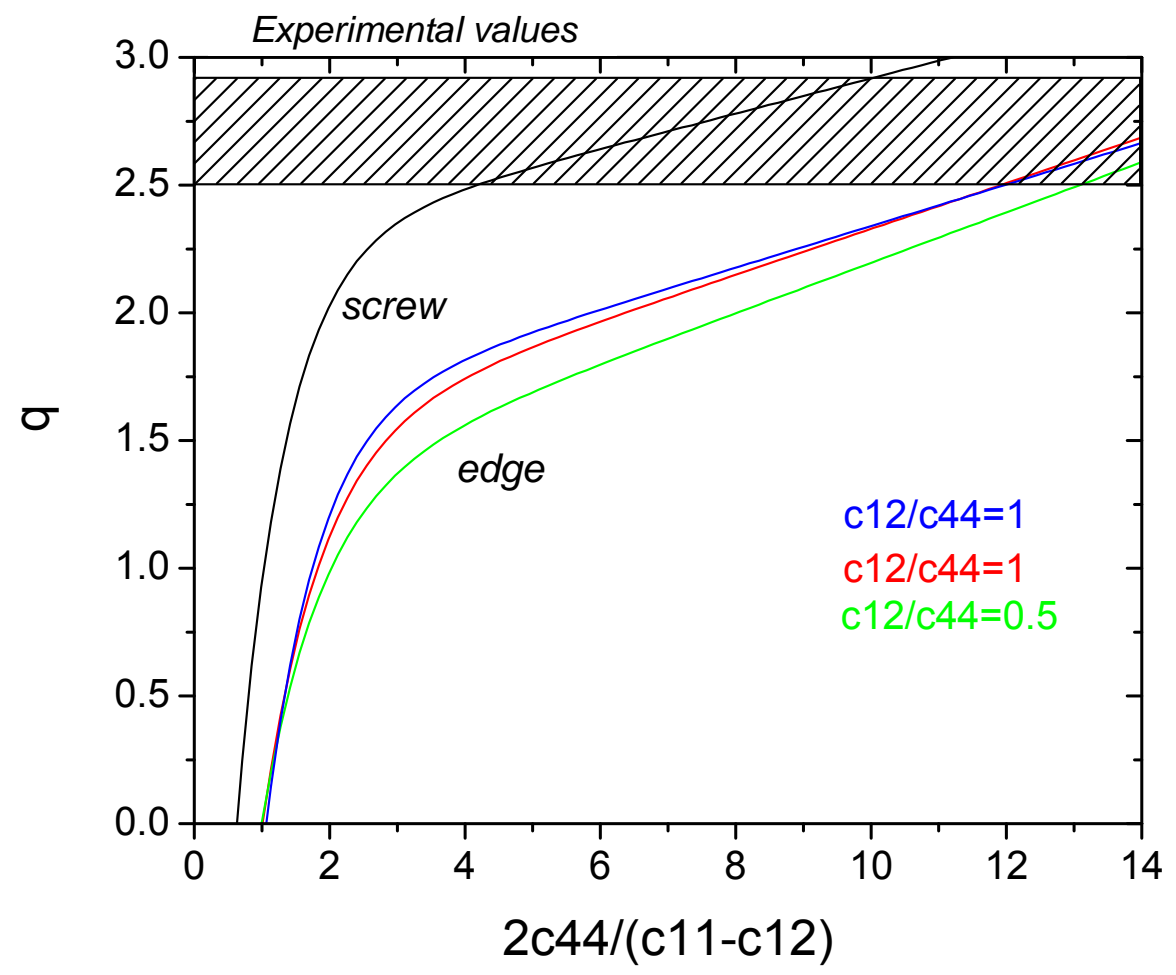

Figure 10: Dependence of parameter $q$ with elastic anisotropy for cubic crystals and dislocation type according to Ref.[38]. The experimental values obtained for $\delta$ hydride of Table 2 are presented as a grey bar. 


\section{Graphical Abstract}
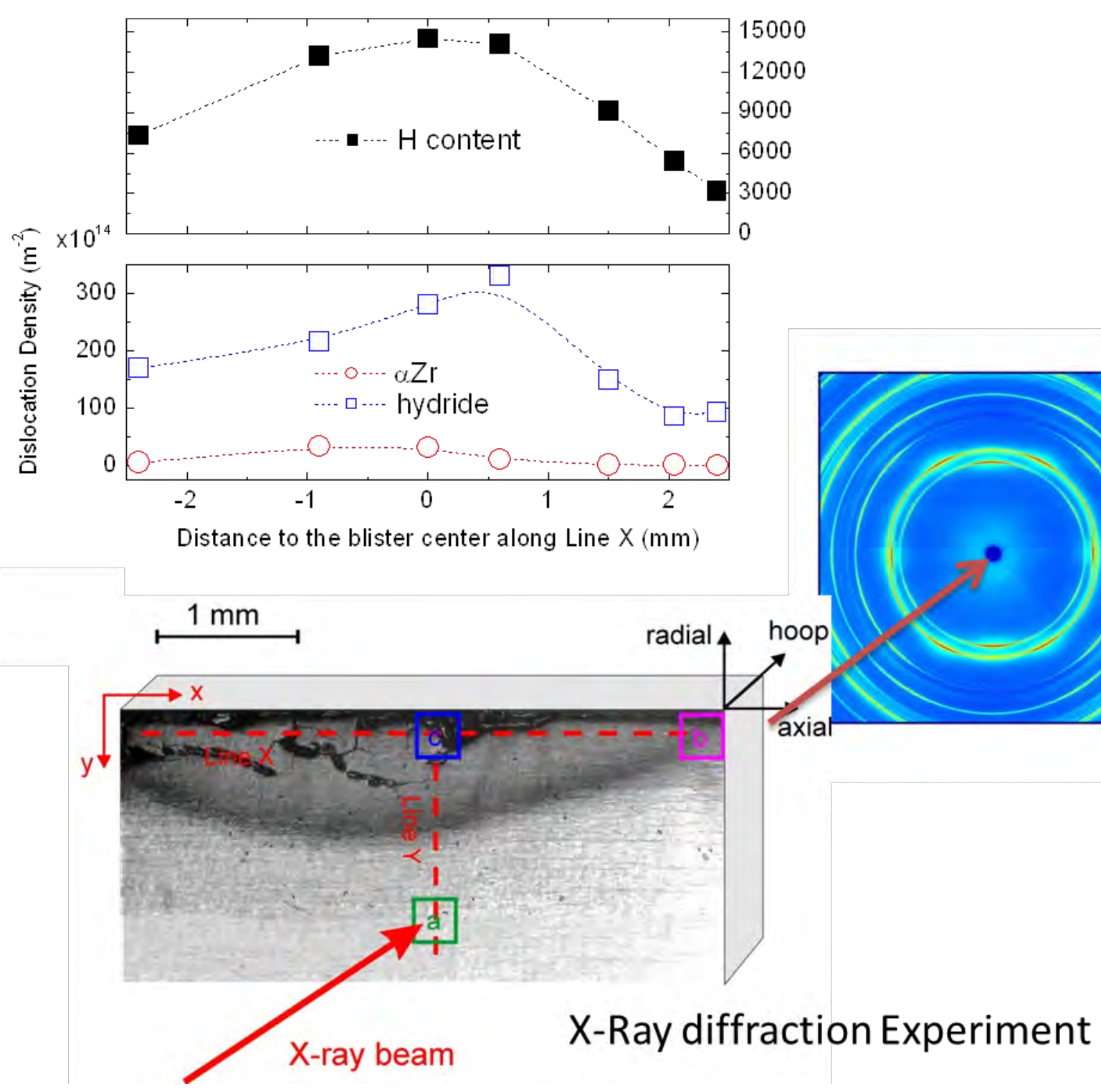